\title{
Hautkrankheiten.
}

\section{Anatomie, allg. Pathologie und Therapie der Haut.}

Fürst. Allgemeiner Fingernagelwechsel bei einem halbjährigen Kinde. (Virchow's Archiv Bd. 96, Heft 3. 1884.)

Fürst sah einen ausgeprägten Nagelwechsel an fast allen Fingern eines halbjührigen reconvalescenten Kindes, das seit Monaten schwere lang anhaltende Krämpfe überstanden hatte, in Folge deren es zuweilen eine halbe Woche nicht möglich war, die krampfhaft contrahirten Finger der fest geschlossenen Hände zu entspannen. Fürst sieht die Ursache der Abnormität in dem anhaltenden Druck, der ungenügenden Reinigung and vielleicht auch in dem neuropathologischen Zastande an sich.

Caspary.

Flemming. Zelltheilung in den Keimschichten des Haares. (Monatshefte für prakt. Dermatologie, Nr. 5, 1884.)

Seitdem durch Fromann, Heitzmann, Klein, Kupffer, Flemming u. A. Max Schultze's Definition der Zelle als eines homogenen kốrnchentragenden Klümpchens für nicht melır zutreffend erwiesen wurde und man vielmehr erkannte, dass die Zellsubstanz aus zweierlei Substanzen bestehe, nämlich 1. aus einem continuirlichen Fadenwerke (Protoplasma Kupffer's, Mitom o. Filarmasse Flemming's), das aber nach Flemming kein Netzwerk ist; 2. aus der Substanz, in welche die erstere eingebettet ist (Paraplasma Kupffer's, Paramitom oder Interfilarmasse Flemming's): seit dieser Zeit wurde auch das bekannte Zelltheilungsschema Remak's als nicht allein zatreffend theilweise verlassen.

Es wurde nämlich nachgewiesen, dass der Kern ans zwei ähnlichen Substanzen wie der Zellkörper bestehe: 1. dem Kerngerüst (Netzwerk) und 2. dem Kernsaft (Zwischensubstanz); in dem letzteren kommen 
noch Nucleoli vor, die nach Fl. vom Kerngerüst sich auch chemisch unterscheiden. Bei vielen Zellen (ob bei allen, ist noch unentschieden) hat Flemming eine Hülle um den Kern, die Kernmembran gefunden.

Das Kerngerüst macht nun bei der Zelltheilung eine Reihe typischer Veränderungen durch, deren Endresultat die Theilung in zwei Fadenmassen ist, deren jede sich zu dem Gerüste je eines Kernes ungestaltet, dann erst erfolgt die Zerklüftung des Zellleibes in zwei Felder (indirecte Zelltheilung oder Mitosis nach Flemming, karyokinetische Zelltheilung nach Schleicher).

Nachdem nun der Verfasser in der Epidermis der Säugethiere Mitosen gefunden hatte, sah er sich veranlasst auch in der Haarmatrix solche zu vermuthen, und fand diese Annahme anch gerechtfertigt.

Durch die Modification einer früher angegebenen Färhemethode brachte Fl. so deutliche Mitosen in den Haarmatrices zur Anschaung, dass dieselben schon bei 100-200facher Vergrösserung sichtbar waren, und zwar in der Matrix des Haares und seiner Cuticula beim Meerschweinchen und Kaninchen, seltener im „peripheren Theil der änsseren Wurzelscheide (Stachelschicht des Haares Unna) ". Aus diesem Verhältniss zieht Fl. den Schluss, dass entsprechend der höheren Leistang der Matrices beim Haarwachsthum, daselbst eine grössere Menge von Kerntheilungsfiguren gefunden werden müssen, während in der Wurzelscheide, die beim Wachsthum keine hervorragende Rolle spielt, nur eine träge Zellvermehrung stattfinde.

In den Matrices ist es nach Fl. nicht die der Papille unmittelbar anliegende Zellenschicht allein, welche Mitosen aufweist, sondern solche finden sich auch 2-3 Zellbreiten von dieser nach oben entfernt, es sei also nicht blos die Papillenmatrixgrenze der Mutterboden des Haares, wie mit Ebner allgemein angenommen wird, sondern derselbe reiche weiter hinauf.

Fl. stellt zum Schlusse weitere Publicationen über die Lage der Theilungsaxen im Haare in Aussicht, und meint, der bisherige Misserfolg beim Anfsuchen der Mitosen sei anf die nicht ganz entwickelt gewesene Färbungstechnik und auf den Umstand zu schieben, dass das zu untersuchende Material nicht ganz frisch und lebenswarm in die fixirenden Reagentien gekommen war.

Fhrmann. 
Einfache (oberflächliche und tiefgreifende oder pllegmonöse $\Lambda$.)

\section{Hautentzündungen.}

Burckhardt. Behandlung des Eczems. (Monatsh. f. prakt. Dorm. Nr. 2, 1885.)

Für die Bohandlung von pustulüsen Gesichts-, Kopf- und Lideczemen, als deren Folgen selır liäufig phlyctänulöse Binde- und Hornhautentzündungen auftreten, empfiehlt Burckhardt die Bepinselung der eczematösen Partien mit $3 \%$ iger Höllonsteinlösung nach vorausgegangener sorgfältiger Erweichung und Ablösung der Krusten. Dieses Verfahren, welches sich B. in einer grossen Zahl von Krankheitsfällen der Augenabtheilung der Charité trefflich bewährt hat, wird anfangs täglich, später jeden zweiten Tag bis zum völligen Schwinden der Hautaffection angewendet. Unterstät»t wird der Verlauf des Heilungsprocesses nach der Angabe des Vurf. durch Applieation einer aus Vaselin $10^{\circ} 0$, Ol. cadini 1.5 und Flor. Zinci 2.0 bestehenden Salbe unnittelbar nach der Aetzung.

$\mathrm{Hochsinger.}$

Sinclair. Gobrauch des lchthyols bei Eczem. (Brit. med. Journ. 22. Nov. 1884.)

Der Verf. hat eine Reihe von Eczemen mit gutem Erfolge mit Ichthyol behandelt, doch müsse dasselbe mit Vorsicht angewendet werden, da er nach Anwendung einer Ichthyolvaselinsalbe (1:5) wegen chronischen Eczems des Kopfes und der Extremitäten bei einem vier Monate alten Kinde zwei Stunden nach der ersten Application tiefe, zwölf Stunden anhaltende, sehr beängstigende Bewusstlosigkeit eintreten sah, die allerdings (! R.) wieder in volle Genesung ausging, jedenfalls aber zur Vorsicht mahne.

Finger.

Landgraf. Magisterium Bismuth $\mathrm{gegen} \mathrm{Eczem.} \mathrm{(Aerztl.} \mathrm{Intel-}$ ligenzblatt Nr. 16, 1883. - Ctlbl. f. kl. Med. Nr. 20, 1884.)

Ein 72jälıriger Mann litt an eincm stark nässenden Eczem der Hände; auf dio erkrankten Stellen warde Mag. Bismuthi in dicker Schicht aufgctragen und darüber Tuchhandschuhe angezogen. In 8 Tagen war das Eczem geheilt. Auch bei Intertrigo der Hautfalten des Halses und der Schenkelbeugen der Neugeborenen und Säuglinge sah L. gute Erfolge von diesem Streupulver. (Wie von anderen auch. A.)

Duhring und Wile. On the pathology of "Paget's Disease" of the nipple. (Am. Journ. of med. sciences. Jnly 1884.) 
D. and W. unterziehen die Pathologie der Paget'schen Erkrankung der Brustwarze einer oingehenden Besprechung, wobei besonders der Zusammenhang und Uebergang derselben mit und zu der carcinomatōsen resp. scirrhösen Veränderang der Brustdrüse erläutert wird. Erstlich werden die bisherigen Arbeiten über diesen Gegenstand, ins. besondere die histologischen Befunde der Autoren wie Thin, Paget, Schweinitz a. A. dorchmustert, worauf die übereinstimmenden Resultate oigener Untersuchungen bekannt gemacht werden, ans denen hervorgeht, dass die erörterte Affection als eine abnorme Proliferation der Retezellen mit secundärer Destruction der Papillen aufuufassen sci, wobei die Epithelwuchernng von der Cutis der Brustwarze aus zunächst auf die kleineren Ausführungsgänge der Milchdrüse übergehe, um von hier aus das ganze Drüsengewebe in atypische Epithelwucherung zu versetzen, und so der erste Schritt zur Carcinombildung gegeben sei. Die Reaction der Papillen und des interacinösen Bindegewebes manifestirt sich durch entzündliche Zellinfiltration desselben mit Nenbildung von jungem Gewebe und später durch consecutive Schrumpfung und Narbengewebsbildung, woraus die scirrhöse Form des Brustkrebses leervorgehe.

Die nabelförmige Retraction der Mamilla sei ein frühes Zeichen der carcinomatösen Erkrankung und erklärt sich durch die obengegcbene Erläuterung.

Hochsinger.

Altschul. Zur Therapie bei Brandwanden der Haut. (Prager med. Wochenschrift Nr. 52, 1884.)

A. hält bei Verbrennungen der Haut für ein unerlässliches Mittel den aseptischen Verband. Da die Verbrennung als solche zwar ein die Entzündung begünstigendes Moment abgibt, nicht aber selbst schon Entzündung sei, so müsse die Aufgabe der Therapie darin bestehen, das Auftreten der Entzündung, die Fiterung und die dadurch erzeúgte Narbenschrumpfung zu verhüten und erst secundär die Schmerzen zu mildern. Diesen Bedingungen entspricht das Jodoform. Aseptischer Verlauf bei frühzeitiger Anwondnug, baldige Sistirung der Eiterung und glatte, weiche Narben selbst bei Schorfbildung sind die Effecte der Jodoformbehandlung.

A. empfiehlt besonders die nach Unna's Vorschrift bereitete Boluspasta: Rp.: Bol. alb. ol. lin. oder ol. oliv. āā 30.00; Liqu. phumb. subacent. 20) no; Jndoform $10-2 \% \%$. 
Bei der Darstellung muss nach Unna's Angabe vorerst Bolus mit Leinöl gemischt werden, da sonst der Bleiessig mit dem Bolus einen unlöslichen Kitt bildet.

Nur bei Verbrennungen ersten Grades eignet sich nach dem Vf. als schmerzstillendes Mittel essigsaure Thonerde. Horovitz.

Rabitsch. Uober die Nilkrätze und die Nilbeule. (Wr. med. Wochenschr. Nr. 49-51. 1884.)

Anatomisch betrachtet, ist die Nilkrätze nach $R$. nichts anderes als ein acutes papulo-resiculöses Eczem, und die sog. Nilbeule nach Ansicht des Verf. eine circumscripte Phlegmone der Haut, aus der Entzündung von Schweissdrüsenknäueln hervorgegangen. Beide Erkrankungsformen, welche mit Vorliebn Fremde, genug oft aber auch die Eingeborenen Aegyptens in den besonders heissen Monaten befallen, sind auf die reizenden und macerirenden Qualităten des bei der enormen Hitze in übermässig reichlicher Menge secernirten Schweisses zurückzuführen.

Die Nilkrätze, das Eczema acut. caloricum, beginnt unter heftigem Jucken in der Regel zuerst an der Stirn mit massenhafter Errption von Miliariabläschen, welche niemals einen eiterigen Inhalt gewinnen, und kann sich von hier aus über den ganzen Körper, als : Brust, Rücken und Extremitäten mit vesiculärer oder papelartiger Efflorescenzbildung verbreiten, mit Ansnahme der Handteller und Fusssohlen, an welchen Stellen dieselbe ganz im Gegensatze zum Nilknoten niemais zur Beobachtung kommt. Bei manchen Individuen geht die Erkrankung unter geeigneter Behandlung rasch zurück, bei anderen führt sie durch häufige Recidive zu chronischen Veränderungen des Hautorganes, zu pruriginösen, lymphangioitischen oder elephantiastischen schwer reparablen Krankheitsformen.

Zur Behandlung eignen sich im papulösen Stadium besonders Theer- oder Naphtholpinselungen.

Die Nilbeule (Bouton du Nil) ist ein Schweissdrüsenfurunkel, der besonders häufig an der Flachhand und der Fusssohle sowie an den Volarseiten der Finger sich etablirt. Bis zu seiner vollen Ent. wicklnng sind in der Regel fünf bis sieben Tage erforderlich.

Die Affection beginnt gewöhnlich mit localisirtem Schmerz an der erkrankenden Stelle, worauf allmählich Schwellung, Röthung und kugelsegmentartige, nie konische Vorwölbung des Epithelstratums, wie 
beim Talgdrüsenfurunkel entsteht, und endlich Aufbruch des Kñotens, gewöhnlich an mehreren Stellen mit Zurücklassung einer vielfach zerklüfteten und nekrotischen Wandung erfolgt. Die Knoten erreichen in der Regel Haselnussgrösse, sind selir schmerzhaft, kommen oft in überans grosser Anzahl an demselben Individunm gleichzeitig vor, und heilen nur nach chirurgischer Eröffnung derselben am besten mittelst tiefer Scalpellincisionen.

Hochsinger.

Rosenbach. Ueber den Zusammenhang von Melliturie and Furankelbildung; nebst Mittheilung eines Falles von Melliturie bei einem 1jährigen Knaben. (D. med. Wochenschrift Nr. 31, 1884. - Centralbl. f. Chir. Nr. 51, 1884.)

Auf Grund beobachteter Fäle von Furunculose, bei denen sich wohl während des Bestehens der Krankheit, nach Ablauf derselben aber nie mehr Zucker im Urin nachweisen liess, glaubt $R$., dass bei solchen, sonst kein Symptom des Diabetes darbietenden Pat. nicht die Melliturie zur Bildung der Karbunkel oder Furunkel geführt habe, sondern dass umgekehrt aus den eiternden Hautaffectionen auf dem Wege der Resorption Zucker oder eine andere stark reducirende Substanz in die Blutbahn und von da in den Harn übergegangen sei.

Eine Analogie für dieses Verhalten der Furnnculose zur Ausscheidung eigenthümlicher Substanzen wäre in dem ev. Auftreten von Pepton im Urin nach Eiterbildungen im Organismus, oder von Albumen im Harn nach Eiterretentionen'zu sehen.

Zur Begründung seiner Ansicht führt R. einen Fall an, bei welchem sich im Verlauf von complicirten Morbillen eine deutliche Zuckerreaction des Urins einstellte, ohne dass der im Beginn der Erkrankung untersuchte Urin des sonst gesunden 1 jährigen Kindes ein derartiges Verhalten gezeigt hatte. Die nach Ablauf des Exanthems auftretende Complication bestand in einer ansgedehnten Furunkeleruption, welcher das Kind auch späterhin erlag.

R. glaubt, dass die Bestätigung seiner Annahme, dass es sich in Fällen dieser Art um Resorption reducirender Substanzen von den Eiterherden aus handle, durch genauere Beobachtung des einschlägigen Materiales bald geliefert sein dürfte.

Dass sich im Verlauf schwerer Diabetesformen in Folge der gestörten Ernährung der Haut oder als Effect von Constitutionsano- 
malien Entzündungen der Haut in den bekannten Formen einstellen, wird natürlich davon nicht berührt.

Duclaux and Heydenreich. Studien über einen Mikroben, welcher bei einem an dem sog. "Clou de Biskra" leidenden Kranken gefunden wurde. (Arch. de physiol. norm. et pathol. Bd. IV. Nr. 6 . p. 106 ff. 1884. - Centralbl. f. klin. Med. Nr. 52, 188t.)

In Paris kam ein Kranker zur Beobachtang, der an dem ,Geschwär von Biskra", einer in A sien verbreiteten Hautkrankheit, litt, welche übertragbar ist, hauptsächlich im September und October auftritt und, mit Knötchen auf der Hant (des Gesichtes, der Hände) beginnend, zu ausgedehnten, mit Krusten sich bedeckenden, nicht sehr tiefen Ulcerationen führt, die erst im Laufe von Monaten unter $\mathrm{Zu}$ rücklassung von starken Narben lieilen.

Die Verff. entnahmen aus der Nachbarschaft der erkrankten Hautpartien des oben erwähnten Kranken Blut und fanden in demselben einen $0,5-1 \mu$ grossen Coccus, bald in Gestalt zweier runder Granula, bald in Gloeaform auftretend. Dieser Coccus wurde in Kalbsbrühe und in neutralem Urin gezüchtet und gedieh bei $35^{\circ}$ bosonders gut.

Hit "Reinculturen" dieses Mlicroorganismus (aus Kalbsbrühe) wurde bei einem Kaninchen eine durch zahlreiche exulcerirende Knütchen charakterisirte, einmal recidivirende Hautlrankheit hervorgerufen. Nachdem diese abgeheilt, wurde das Thier paralytisch und starb einige Zeit später.

Bei späteren Versuchen erzielten die Verff. aber ganz abweichende Resultate. $J_{\theta}$ nach dem Alter der angewanảten Culturen nämlich und anch je nach der Art der Application (subcutane Impfung, directe Injection ins Blut) bekamen sie entweder ganz rasch tödtlich verlaufende Erkrankungen mit ausgebreiteten Fibringerinnungen in den Lungengefässen und colossaler eitriger Pericarditis, oder anfangs nur geringfügige Localerscheinungen, im Lanfo von Tagen und Wochen aber eine Art chronischer Pyämie mit vorwiegenden osteomyeliti. schen Eiterungen, vorzüglich in den Lendenwirbeln, im letzteren Falle meist gefolgt von hämorrhagischer Spinalmeningitis. Diese letzteren Veränderungen führten zu eigenthümlichen paralytischen Erscheinungen.

Die Erklärung dieser verschiedenartigen Wirkungen desselben 
Mikroben wird von den Verff. in den modifieirenden Einflüssen länger danernder Culturen ("Virus atténuéc) etc. gesucht. Die Verff. lassen übrigens die Frage offen, ob sie in ihrem Mikroben wirklich schon das Contaginm des Geschwürs von Biskra dargestellt haben.

Da sie nicht auf festen Nährboden züchteten, so fragt es sich wohl, ob sie in allen ihren verschiedenen Experimenten immer dasselbe Virus vor sich gehabt haben. Jedenfalls sind aber die hervorgebrachten Erkrankungen, besonders die osteomyelitischen Processe an sich der Beachtung werth.

Cavafy. Fälle von Gesichtserysipel bei niederer Temperatur. (Brit. med. Journ. Nr. 1213, 29. März 1884.)

Verf. betont, dass die bedeutenden Verschiedenheiten im Verlauf des Erysipols die $\Lambda$ ufstellung verschiedener Formen veranlasst haben. In der Regel werde es wohl von einem oder mehreren Frösten eingeleitet, von intermittirendem Fieber begleitet, das mit der Eruption gleichzeitig auftritt and der Ausbreitung der Hautentzündung an In. tonsität proportional ist. Doch auch das Fieber kann verschiedene Typen darbieten, es kann der Eruption des Erysipels 1-2 Tage voransgehen, remittirenden oder intermittirenden Typus darbieten, es kann der Intensität der localen Erscheinungen gegenüber verhältnissmässig intensiv oder auffallend gering sein. Ja das Fieber kann selbst fellen, and $\mathrm{C}$. theilt nun fünf Fälle mit, in denen trotz bedeutender ortlicher Erscheinungen sogar subnormale Temperafuren beobachtet wurden, obwohl der Eruption des Erysipels in drei Fällen Fröste vorausgingen und zwei der Patienten das erstemal von Erysipel heimgesucht wurden, wo es ja in der Regel intensiver aufzutreten pflegt. Verfasser bespricht hierauf die Aetiologie des Frysipels, die Versuche von Tillmann and Fehleisen und betont, dass, da der contagiöse Charakter des Erysipels sicher sei, in jedem Falle darauf Rücksicht za nehmen sein werde.

Finger.

Rosenthal. Zur Charakteristik des Erysipels. (Wr. med. Presse Nr. 40, 1884.)

An zwei Fällen von Wander-Erysipel, die ohne nachweisbare Läsion des Hautorganes, der Mund-und Nasenhöhlenschleimhaut sich entwickelten, kountc $R$. sich überzeug $€ n$, dass beim Fortschreiten der 
Rose die noch weiter gelegenen Stellen erhöhte mechanische und elektrische Empfindlichkeit und örtliche Temperatursteigerung darboten, somit eine Gewebsreizung erschliessen lassen, noch bevor das Erysipel an diesen Stellen in Erscheinung trat. Auch Schwellung and Schmerzhaftigkeit der angrenzenden Lymphdrüsen eilen der erysipelatösen Entzündung voraus. Die in Rede stehenden zwei Fälle zeichneten sich durch den langwierigen Verlauf ans. R. hält die cutanen Blat- and Lymphgefässbahnen als massgebend für die Ausbreitang des erysipelatösen Processes. Es gelang ihm in zwei Fällen durch Compression der Gliedmassen ein im Fortschreiten begriffenes Erysipel einzudämmen; ebenso sei es möglich gowesen, nach Injection von acht Pravaz'schen Spritzen einer $5 \%$ igen Borsäurelösung ein Erysipel zur Räckbildung zu bringen.

R. beobachtete in einem Falle Symptome der acuten Nephritis, ein andermal eine hämorrhagische Enteritis; ferner. vorüborgehende, hochgradige Muskelhyperästhesie und in einem Falle nach Ablauf des Erysipels Anästhesie des linken Nervus cutaneus fomoris externas. In einem dritten Falle kam es zur Thrombose dos Sinus cavernosus. Als Therapie empfiehlt er salicylsaures Natron oder das leichter verdau. liche Präparat salicylsaures Chinin.

Horovitz.

Janicke und Neisser. Exitus letalis nach Erysipelimpfung bei inoperablem Mammacarcinom und mikroskopischer Bofund des geimpften Carcinoms. (Centralbl. f. Chir. Nr.25, 1884.)

Gestützt auf die Erfahrungen Busch's und Volkmann's einerseits, anderseits ermuthigt durch Fehleisen's theilweise Erfolge bei seinen bekannten Versuchen mit Erysipelimpfung (siehe d. Viertelj. 1882, pag. 116 u. 513 und 1883, pag. 128) versuchten die Antoren ebenfalls die Impfung des Erysipels gegen ein inoperables, schon mehrmals operirt gewesenes Carcinom der linken Brustdrüse einer vierzig Jahre alten Frau.

Es waren schon Krebsmetastasen in den Achselhöhlen und Halsdrüsen zu constatiren und da gegen die immer heftiger auftretenden Schmerzen das Morphium nicht vertragen wurde, so machte $J$. die Impfung mit von Fehleisen zugesandter Fleischinfusgelatine-Erysipel-Caltur. Ein $1 \square$ Ctm. grosses Hautstück über dem Carcinom wurde horizontal und vertieal scarificirt und in dasselbe ein stecknadelkopfgrosses Culturstück verrieben. Schon am selben Abend trat in Sehüttelfrost und eine Temperaturerhöhung auf $40 \cdot 2$ ein. Der 
weitere Verlauf war so fulminant, dass schon am vierten Tage Collaps und der Tod ohne Zutritt einer weiteren besonderen Complication erfolgte. Die Section wurde nicht gestattet. Die früher derbharten Tumormassen schwanden zum Theile unter dem Erysipeleinflusse, zum Theile wurden sie weich. Die mikroskopische Untersuchung der ausgeschnittenen Stücke ergab das Vorhandensein eines Bindegewebskrebses and Scirrhus. Schon eine schwache Vergrösserung ergab, dass in der Nähe der Krebsnester nnregelmässig angeordnete Struifen und Herde auftraten. Bei starker Vergrösserung lösen sich jene Streifen und Herde in Massen von Coccen anf, dio in verschiedenon Biegungen und Krümmüngen durcheinander geschlungen und in Reihen als Diplococcen neben einander angeordnet erscheinen. Entsprechend der Ausbreitung der Coccen ist cine $\Lambda$ bnahme der Krebsnester zu constatiren.

Horovitz.

\section{Angioneurosen der Haut (Dormatosen mit vorwaltend ausgeprägter Störung des Gefässtonus. A.)}

0llivier. La Rougéole à Paris. (Arch. génér. de méd. Supt. 1884.)

O. hebt gegenüber der gewöhnlichen Anschauung von der Benignität der II asern deren Gefahr hervor, und belegt seine Behauptung durch statistische Daten, aus welchen ersichtlich wird, dass zwei Percent der Pariser Kindermortalität im Jahre 1883 durch diese Krankheit verursacht war. Er ist daher für die strenge Separirung der gesunden Kinder von den kranken.

Horovitz.

Discussion über den Scharlach in der Harveian Suc. of London, Sitzung vom 3. April 1884. (Brit. med. Journ. Nr. 1216, S. 763, 19. April 1884:)

Lawrence leitet die Discussion mit folgonden Bemerkungen ein. Erstens: Aetiologie. Das Virus des Scharlach sei zweifullos spocifisch, wie die mikroskopische Untersuchung des Blutes und die Möglichkeit, durch Injection desselben bei Thicren oder Ueberimpfung auf Menschen dieselbe Erkrankung za erzeugen, beweisen.

Die schuppende Hant sei eines der wichtigsten Mittel und Wege, auf dem Scharlach übertragen werde. Die wichtigsten Charakteristica des Virus sind Flüchtigkeit, Haltbarkeit, Uebertragbarkeit auf Gesunde.

Zweitens: Chirurgischer Scharlach. Sece notirto 1858 ein Scharlaclificber, welches auf Traclicotomien folgtc. Weitere Arbeitcu 
bewiesen gleichfalls, dass Scharlachfieber nnmittelbar anf Operationen folgen könne; dass es Verschiedenheiten des Verlaufes darbiete; dass es dis Wundheilung mehr weniger verzögere; dass endlich auch andere Hauterkrankungen, als Scharlachfieber auf eine Operation folgen können.

Drittens: Puerperales Scharlachfieber hat eine Incubation von 24-48 Stunden; L. berichtet in dieser Beziehung über 5 Gebärende, welche von Scharlachfieber befallen wurden. Eine Mutter blinb verschont, obwohl ein schweres Scharlachfieber ihr in der Woche ilher Niederkunft 4 Kinder raubte, die anderen vier Mütter heilten nach schweren Formen, ein Kind starb, zwei blieben frei, zwei genasen.

Zum Schluss besprach L. die Differentialdiagnose zwischen Scharlach und Masern.

Broadbent ist der Ueberzeugung, das Virus sei ein organisches. Mit Rücksicht auf das chirurgische Scharlachfieber bemerkt or, dass Kranke, die durch Operationen herabgekommen sind, für das Virus vielleicht empfänglicher seien.

Mahomed betont, dor Charakter des Scharlachs sei stellenweise ein endemischer, es sei dann nicht eine Berührung mit Kranken, sondern eine Entwicklung inmer wieder in demselben. Hause, derselben Gegend zu beobachten, was für eine spontane Entwicklung aus anfänglich ungefährlichen Keimen spreche. Sicher hafte das Virus an den Schuppen und habe er Fälle gẽsehen, in denen leichte Schuppen noch nach eilf Wochen seit Beginn der Erkrankung eine Ansteckung vermittelten. Das chirurgische Scharlachfieber sei dem anderen vollkommen identisch und biete meist leichten Verlauf dar. Puerperale Weiber seien für das Scharlachvirus sehr empfänglich, auch verlaufe die Erkrankung meist schwer.

Pepper erklärt die kurze Ineubation in den chirurgischen Fallen durch die Aufnahme durch offene Wunden.

Finger.

Parker. Verwandtschaft $\mathrm{z}$ wischen Scarlatina und Diphtherie. (Brit. med. Journ., S. 1090, 7. Juni. 1884.)

P. hat im letzten Winter ein zehnjähriges Mädchen an schwerer Diphtherie behạndelt, bei dem die sorgfältigste Untersuchung mit Rücksicht auf die Infectionsquelle nnr den Besuch eines scharlachkranken Kindes müglich erscheinen! liess. Vf. kennt bisher keinen Fall, 
in welchem Scharlach durch Berührung mit diphtheritischem Gifte veranlasst worden wäre, war aber mehrmals in der Lage, schwere Anfälle von Diphtherie auf keine andere Quelle, als die Berührung mit Scharlachkranken zurūckführen zu künnen. Die Verwandtschaft zwischen diesen beiden Erkrankungen ist dem Vf. auf das hin zweifellos.

Finger.

Leale. Scharlach des Fötus und der. Mutter im neunten Schwangerschaftsmonate. (Med. news 31. Mai 1884.)

Durch Einschleppung des Scharlachs in eine gesunde Familio erkrankten erst der vierjährige Sohn, sodann die im neunten Schwangerschaftsmonate stehende Mutter und endlich die Amme. Während bei dem Sohne und der Amme die Krankheit gat ablief, trat bei der Schwangeren ein heftiges Exanthem und hohes Fieber auf, weshalb die künstliche Unterbrechnng der Schwangerschaft eingeleitet werden musste. Nach vierundzwanzig Stunden jedoch traten Delirien auf, und die Frau starb unter den Erscheinungen der Herzschwäche. Das Kind kam mit einer dunkelrothgefärbten Haut zur Welt, hatte Hyperamie der Rachenschleimhaut und Fieber; zehn Tage nach der Geburt Abschuppung, Albuminurie und Fautödem. Das Kind blieb am Leben.

Horovitz.

Wildermuth. Ueber das Auftreten chronisch-epilept. Zustände nach Scharlach. (Würtemb. med. Correspondenzblatt Nr. 35 und 36,1884 .)

Zwölf Fälle von schweren Scharlacherkrankungen, die mit Delirien und anderen Hirnerscheinungen einhergingen, brachten $W$. zur Annabme, die später beobachteten epileptischen Erscheinungen als vom Scharlachprocesse abhängig anzusehen. Hereditäre Belastung war in vier Fällen zu constatiren. In einigen Fällen konnten schon frühzeitig epileptische Zufälle nachgewiesen werden, während bei einigen anderen erst nach dem Auftreten von deutlichen psychischen Verän. dernngen die epileptischen Zustände zur Entwicklung kamen. Im Anfange sind es die Erscheinungen des petit mal, späterhin sind es typische epileptiforme Anfälle. In zwei zur Nelroskopie gelangten Fällen war Convexitätsmeningitis und chronischer Hydrocephalus zu verzeichnen. 
Patin. Scharlach bei Verwundeten. (Sonderabdr., Würzburg 1884.) Patin beobachtete in drei Fällen von Hatverletzungen ein dem Scharlachexantheme ähnliches Krankheitsbild der allgemeinen Hautdecke. Nach kurzem Bestande des Exanthemes trat längstens am vierten Tage Abschilferung der Haut auf, woranf noch Albuminurie sich hinzugesellte.

In allen drei Fällen trat Genesung ein.

Merkwürdig ist der Umstand, dass das angebliche Scarlatinabild von der verletzten Haatstelle aus sich immer weiter verbreitete. - (Diese Fälle tragen keineswegs daza bei, die Zweifel Derjenigen, welche von der Existenz des chirurgischen Scharlachs nicht überzeugt sind, zu zerstrenen. R.)

Horovitz.

Moellmann. Beiträge zur Pathologie der Scarlatina. (Berl. klin. Woch. Nr. 26, 1884.)

Moellmann gibt einen eingehenden und übersichtlichen Bericht über eine schwere mehrjährige $S$ charlachepidemie in Simmern und Umgegend, während deren er allein 493 Fälle (auf 38 Ortschaften vertheilt) beobichtete. Indem auf das Original verwiesen wird, sei nur herrorgehoben, dass $M$. in einem Falle, der ein sechsjähriges Mädchen betraf, Morbillen am 13. Tage eines schweren Scharlachs mit intensiv diphtheritischer Angina ausbrechen sah; dass in 12 Procent (61 Fällen) Scarlatina sine exanthemate bestand; dass die schwersten, meist tödtlichen Affectionen des Nervensystems mit geringer oder selbst fehlender Temperatursteigerung einhergingen; dass in einem Falle die Nephritis chronisch warde und nach 4 Monaten zum Tode führte. - Wenn M. (in Uebereinstimmung mit Henoch) die Scharlachdiphtheritis von der genuinen Diphtheritis verschieden hält und $\operatorname{di} \theta$ Nephritis bei Scharlach anders verlaufend findet als bei Diphtheritis, so kann Referent, der im letzten Winter eine schwere Scharlachepidemie in Königsberg beobachtet hat (etwa 60 eigene Fälle), diese Ansicht nicht theilen, aber auch an diesem Orte nicht bekämpfen.

Caspary.

Heubner und Bahrdt. Zur Kenntniss der Gelenkeiterungen bei Scharlach. (Berliner klin. Wochenschr. Nr. 44, 1884.)

Löffler hatte (im 2. Bande der Mittheilungen ans dem dentschen Reichsgesundheitsamt) die interessante Thatsache mitgetheilt, dass in den Membranen der Scharlachdiphtherie ein "kettenbildender 
Coccus" einen sehr guten Nährboden und reichliche Entwickung biete, dieser lasse sich unschwer rein züchten und seine Reinculturen, wenn sie thierischen Organismen direct in die Blutbahn gespritzt wurden, riefen schwere, eiterige Entzündungen zahlreicher Gelenke hervor, in denen die Coccen wieder nachweisbar waren, während die gleichen Mikroorganismen, wenn sie einfach subcutan verimpft wurden, nur eine locale erysipelartige Affection, nicht aber die erwähnte allgemeine Infection erzeugten. Im Hiaweis darauf veröffentlichen Heubner und Bahrdt die Krankengeschichte eines 14jährigen Patienten, der am 16. Tage eines schweren Scharlach nach scheinbar glücklich abgelaufener Diphtheritis faucium (et cutis) nnter Eiterbildung in mehreren Gelenken, Pericarditis, hämorrhagischer Nephritis erlag. Schon während des Lebens waren einzelne Partien des Belags, welcher sich am 7. Krankheitstage auf der Hant des Hodensackes gebildet hatte, abgehoben und untersucht worden. Hier fand sich nun in dem eigentlichen Exsudat eine einzige Bacterienform, diese aber äusserst reichlich: dieselben Kettencoccen, gleichmässig runder Organismen zu äusserst lang gewundenen Ketten, Schlingen und Knäneln entwickelt, wie sie L $\hat{o}_{\mathrm{ffl}} \mathrm{er}$ beschrieben hat. Da diese Organismen in der zollarmen oberen Hülfte des croupösen Exsudats in überraschender Reichlichkeit and Reinheit vorhanden sind, in der Tiefo bci mehr Zellreichthum viel zerstreuter erscheinen, um in den dom Papillarkörper am nächsten liegenden Zonen ganz zu verschwinden, ist es kaum zweifelhaft, dass diese Organismen secundär auf dem vorgängigen Exsudate gewuchert sind. Während nun diese Hautdiphtheritis in wenigen Tagen unter Borsäurebehạndlung heilte, während die schwere Mandelaffection unter parenchymatösen Injectionen 3percentiger Carbolsäurelösung anscheinend glücklich ablief, zeigte die Obduction eine Todesursache, die mit Wahrscheinlichkeit auf Invasion jener KettenCoccen in das Blut zurückzuführen war. An den dem Auge während des Lebens nicht zugänglichen, am weitesten nach hinten und unten gelegenen Partien der rechten T'onsille bestand noch eine eiterigo Infiltration von geringer Ausdehnung und setzte sich von hier durch die Tonsillenkapsel nach der retropharyngealen Gegend fort. Hier schloss sich eine ausgebreitete eitrige Infiltration des intermusculären und musculären Gewebes der rechten Halsseite an; der Process setzte sich fort auf die Vena jugularis dextra communis und hatte zn einer ausgedehnten eiterigen Thrombophlebitis in derselben geführt. An 
den Wänden des Ganges von der 'Tonsille zu der thrombosirten Vene waren dieselben zierlichen Kettchen nach\%uw isen, die in der Hautmem bran gefunden waren; ebenso fanden sich im Blute selbst reichlich theils dichte Knäuel verschlungener Ketten, theils einzelne, lange Perlschnüre 2wischen den rothen Zellen des Leichenblutes. Analog den Löfflerischen Experimenten waren nun auch im Gelenkeiter und in dem fibri. nōsen Exsudate des Herzblates dieselben Coccen, wie auch an diesen beiden Stellen so lange Ketten sich nicht entwickelt hatten, sondern Diplococcen bis höclıstens 10 oder 12gliedrige Ketten. Sonach sind die Autoren geneigt. die unglückliche Wendung dieses Scharlachfalles, speciell die poliarthritischen Eiternngen auf die secundäre Invasion eines Mikroparasiten in das Blat zu beziehen, der auf diphtheritischer Tonsillarmembran seinen Nährboden gefunden hatte. Caspary.

Commins. Fall von puerperaler Scarlatina mit hyperpyreti. scher Temperaturdurch dieKaltwasserkur erfolgreich behandelt. (Brit. med. Journ. Nr. 1226, S. 760, 19. April 1884.)

Frau C. wurde sieben Tage nach einer glücklichen Entbindung. von hohem Fieber $\left(40^{\circ} \mathrm{C}.\right)$, und Tags darauf von scarlatinösem Exanthem befall(n. Die Temperatur stieg in den nächsten zwei Tagen bis auf $41^{\theta}$ C., der Puls und die Respiration wurden schwach, Pat. war sehr nuatt, das Exanthem selur ausgebreitet, stellunwoise confluirend, dunkelroth, die Pat., obwohl bei Bewusstsein, lag apathisch und verfallen da.

Commins verordnete Einpackungen in 'Tücher, die in möglichst kaltes Wasser getaucht wurden, und setzte dies durch $1 \frac{1}{2}-2$ Stunden fort, bis die Temperatur auf $39^{\circ} \mathrm{C}$. sank. In dieser Weise wurde Patientin durch zehn Tage behandelt, dabei Cognac and Chinin innerlich gereicht. Pat. erholte sich, das Exanthem schwand und war von bedeutender Abschuppung gefolgt. Auffallend war dem Autor das Freibleiben von Rachen und Schlund trotz der intensiven Erkrankung, so dass C. zunächst an eine von Scarlatina verschiedene Erkrankung dachte, doch der Unstand, dass zur Zeit gerade Scharlach herrschte and eines der drei Kinder der Frau sich von der Mutter mit Scharlach inficirte, war ein Beweis, dass is sich um diese Erkrankung handle. Den etwas abnormen Verlanf und das hohe Fieber schirbt C. auf den puerperalen Znstand der Fran, dei für die Infection in hohem Grade empfänglich mache. 
Bennett. Zur Therapie der Scarlatina. (Brit. med. Journ. 23. Aagust, 1884.)

Entgegen der Warnung Well's, dass die Darreichnng von Pargantien während der Eruptionsperiode der Scarlatina bei daselbst eingetretener Stnhlverstopfung von sehr unangenehmen Erscheinungen gefolgt sein könne, hebt B. hervor, er habe in einer grossen Zahl von Fällen Purgantien ohne Nachtheil gereicht, ja dieselben üben, bei Stuhlverstopfung verordnet, auf den Verlauf des Processes einen günstigen Einfluss.

Finger.

Comby. L'exanthème de la varic elle. (Progrès méd. Nr. 30, 1884.)

Comby beschreibt drei Fälle von Varicellen, bei denen das Exanthem sich auf der Mundschleimhaut, der Zunge, Conjunctiva und Vulva localisirte, und von welchen der dritte Fall durch eine heftige ulceröse Stomatitis sich noch überdies anszeichnete. Horovitz.

Rasch. Nephritis nach Varicellen. ('Tijdskrift for praktisk Medicin $\mathrm{Nr} .4,1884$.)

Verf. theilt eine sich schon rom Jahre 1865 datironde Beobachtung von Nephritis nach Varicellen mit. Bei einem 2jährigen Knaben sind am 3. September die Varicellen ansgeschlagen; am 11. Sept. bemerkte die Mutter, dass das Kind ein gedunsenes Gesicht hatte, schläfrig und matt war, viel Durst und wenig Appetit hatte. Als Verf. am 12. Sept. den Pat. wieder sah, war fortwährend Oedem des Gesichtes und den unteren Extremitäten vorhanden. Im gelbbraunen Urin wurde Eiweiss, Blutkörperchen and ziemlich zahlreiche Epithelcylinder nachgewiesen. Am 21. Sept. war nach Anwendung warmer Bäder und einer Sol. acet. ammon. das Oedem geschwunden, und der jetzt licht gewordene Urin enthielt nur Spuren von Eiweiss und wenige Cylinder; am 24. Sept. war der Urin ganz normal.

Boldomero-Sommer. Einige Notizen über die Blattern in Buenos-Ayres und die Blattern der Indianer. (Monatsh. f. prakt. Dermatologie Bd. III, Nr. 12, 1884.)

Nach Dr. Sommer treten in Buenos-Ayres liäufige und schwere Blattern-Fpidemien auf. Die Ursache sei erstens der Mangel des Impf $z$ wanges, zweitens die Verschleppung des Krankheitskeimes durch die Indianer. 
Die Indianer seien eben wegen des Mangels jeder Impfung sehr empfänglich für die Infection mit dom Blatterngifte und nohmen auf ihren Zügen durch Städte und Dörfer den Krankheitskeim in sich anf. So entstanden auch die zwei letzten sehr devastirenden Epidemien durch die nach Burnos-Ayres gefangen gebrachten Indianer. Von diesen selbst ist die Krnnkheit sehr gefürchtet, so dass sie, wenn ein Fall in der Wildniss vorkommt, entweder wegziehen, oder den Kranken, in ein Fell geschlossen, von Pferden weit wegschleifen lassen, um ihn dann seinem Schicksale za überlassen. Die Form, unter welcher die Blattern bei den Indianern auftreten, sei die hämorrhagische; confluente Blasen von einigen Centimetern im Durchmesser keine Seltenheit. $95 \%$ enden letal.

Neuester Zeit mache sich der segensreiche Einfluss der Impfung erstens durch mildere Form, zweitens durch Seltenheit des Auftretens geltend. Sommer's Collage Penna fand in der Terpontinessenz (täglich 6.00 in Gummilösung) ein Mittel, welches bei der hämorrhagischen Form der Blattern nicht nur die Zunalıme der Hämorrhagie hemme, sondern in manchen Fillen sogar rettend wirke (? ? ? A.).

Neumann. Purpura variolosa, Variola vera und Variola sine exanthemate in einer Familie. (Dentsche med. Wochenschrift Nr. 43,1884 .)

Im Anschlusse an eine stets mit norvösen Erscheinungen verlanfende Menstruation traten bei einer 27 Jahre alten Person Kopfschmer\%en, Mattigkeit und Muskelzuckungen auf, zu welchen sich nach weiteren 3 Tagen ein Schüttelfrost und eine 'Temperaturerhebung auf $40 \cdot 5$ hinzugrsellten. Gleichzeitig Eruption eines scharlachartigen Exanthems im Gesichte und auf den Extremitäten, das bald schwand um einer Quaddeleruption Platz zu machen. Anhaltend hohes Fieber, 120 Pulsschläge and heftige Kreuzschmerzen. Am fünften und sechsten Krankheitstage Schüttelfröste. Frbrechen und Präcordialschmerzen; Sensorium frei. Am siebenten Tage Blutungen in die Conjunctiva bulbi links, Blutungen aus der Rachenschleimhaut, blutiges Erbrechen und endlich Blutungen aus den Harn- und Geschlechtsorganen. Am achten Tage trat der Tod ein, nachdem noch zuvor punktförmige Blataustritte in die Unterbanchgegend sich eingi'stellt hatten.

Etwa zwei Wochen rach Beginn dieses Falles erkrankte die 17jährige Schwester mit den gleichen initialen allgemeinen und en- 
tanen Erscheinungen, nur dass auch sofort Schüttelfröste einsetzten. Es kam zu keiner Pockenbildung und unter Abnahme des Fiebers und der Schmerzen erfolgte die Genesung. Trotz sofort rorgenommener Impfung der ganzen Familie erkrankte auch die dritte Schwo. ster. Fehlen des Initialexantliems. Nach dreitägigem hohem Fieber zeigten sich rothe Flecke, aus welchen das Variolaexanthem sich entwickelte. Im Weiteren normaler Verlauf einer schweren Variola vera confluens. Genesung.

Horovitz.

J. Heitzmann. Vicarirende Menstruation and MenstrualExantheme. (Wr. med. Jahrb. 1884.)

Sowohl aus Heitzmann's, als anch ans den von ilım ange. führten fremden Beobachtungen geht hervor, dass zur Zeit der Menstruation nicht die Geschlechtsorgane allein sich im Zustande der Congestion befinden und dass bei vorkommender Behindernng des. Blutabganges aus der Schleimliaut des Uterus das Gleichgewicht der Blutvertheilung darch Ergüssa an anderen Stellen compensirt werde. In Anbetracht dessen, dass die weiblichen Genitalorgane in einem gewissen Reciprocitäts-Verhältnisse zur Hautdecke stehen (Chloasmata aterina, Behaarung gewisser Körperregionen und Pubertăt, Bläschen-, Blasen- und Knötchenproruption und Sexualleiden etc.) ist es erklärlich, wenn gewisse Functionsstörungen der Uterusschleimhaut mit ungewöhnlichen cutanen Erscheinungen ausgeglichen werden. Dem entsprechend konnten sowohl $H$. als auch andere Beobachter constatiren, dass bei Amenorrhö日 Sugillationen, Ecchymosen, Petechien, erythemartige Efflorescenzen, urticariaartige Hautblüthen und Papeln an verschiedenen Körpertheilen in regelmässigen, periodisch sich wiederholenden Zeiträumen auftraten nnd verschwanden. Mit Behebung der Ursachen dieser anomalen Menopause trat regelmässiger Blutabfluss ans dem Uterus auf und die Veränderungen an der Hautdecke kamen nicht zum Vorschein, $H$. ist daher der Ansicht, dass das Ausbleiben der menstrualen Blutung und die vicarirenden $\mathrm{Er}$ scheinungen der Haut Folgen einer und derselben Störung in den Functionen des Gesammtorganismus sind. Horovitz.

Spencer. Fall von Erythema multiforme. (Brit. med. Journ. 6. Sept. 1884.)

Eine neunzehnjährige, schwache, anämische Blondine klagte nach anstrengender Arbeit meltrere Tage über Schmerz im Kreuz, in 
den Gliedern, Kopfschmerz, Husten. Vier Tage nach Beginn der Erkrankung traten einige Flecke am Handrücken anf, die sich am sechsten Tage in Form linsengrosser, ovaler, rother Knötchen auch über Extremitäten, Nacken und Brust verbreiteten, welche über den Handgelenken, Knien, Ellbogen, am dichtesten standen, an Stirn und Bauch fehlten. Diese Papeln nahmen rasch an Grösse za, confluirten und nahmen im Centrum livide Farbe an. Am achten Tage begann der Ausschlag abzublassen und war ain elften Tage geschwunden. Allgemeinsymptome, hohes Fieber, das sich zwischen 39.5 und 40 hielt. Puls von 110-120, Kreuzschmerzen hätten an Variola denken lassen kōnnen, wenn nicht die Form des Exanthemes für Erythem den Ausschlag gegeben hätte. (Was ist denn daran Besonderes? A.)

ollivier. Hauteruptionen neben Chorea and Rhenmatismus. (Gaz. des Hôpitaux Nr. 63, 1884.)

Ein dreizehnjähriges Kind zeigte eine typische Chorea, welche auch die Gesichtsmuskeln betraf, daneben Schmerzen in den Kniegelenken und Herzaffection. Im Verlaufe der Erkrankung entwickelte sich ein polymorphes Exanthem, welches aus grösseren und kleineren Flecken ond Knötchen bestand, am Rumpfe und an den Extrenitäten von mässigem Jucken begleitet.

Bei einer zweiten Kranken desselben Alters war eino urticariaähnliche Hautaffection das erste Symptom des Processes, Schmerzen und Röthung der Handgelenke folgten nach einigen Tagen nach, woran sich erst eine hartnäckige and recidivirende Chorea schloss. Es liegt nahe, in der Chorea, den Hauteruptionen und den Gelenksaffectionen Localisationen desselben Processes zu sehen. Froud-Wien.

Gamberini. Fall von polymorphem Erythema exsudativum, durch Bromeinfluss bedingt. (Rivista intern. di Medic. 1884. Giom. ital. delle mal. ven. e della pelle 2. 1884.)

Eine 25jährige Wärterin war bis in ihr 21. Lebensjahr stets gesund, um diese Zeit fing sie an, häufig an Kopfschmerz zu leiden, der auf den Gebrauch von grossen Dosen Bromkali sistirte; nach etwa einẹm Monat des Gebrauches des Bromkali erschienen auf den Beinen blaurothe, rundliche Flecke, die stellenweise über die Haut erhaben waren, juckten, spontan schwanden, wenn der Gebrauch des Bromkali ausgesetzt wurde. 
Vier Monate nachdem der Kopfschmerz geheilt war, fing sie an an heftigem Schwindel zu leiden, der in kurzen Intervallen wiederkelbrte. Nach zweimonatlichem Gebrauch des Bromkali liess der Schwindel nach, der Ausschlag kehrte wieder. 5 Monate später kamen ncbst Schwindel auch Convulsionen, Verlust des Bewnsstseins.

Auch diesmal brachte Bromkali Erleichterung, doch kehrten die Anfülle, wenn es ausgesetat wurde, stets wieder, weshalb Pat. continuirlich Bromkali nahm. Die Hautausschläge kehrten nun zu verschiedenen Zeiten wieder, immer an den Füssen, sie vermehrten und verschlimmerten sich bedeutend. Neben den Flecken traten Blasen und ausgebreitete, blaurothe Ulcerationen auf, die aratlicher Behandlung widerstanden.

Die Patientin wurde mit Chininarsen in Tagesdosen von 0.10 und örtlich mit Salz Salpetersäuro-Bädern (Acid. nitric.; acid. muriat. āa $20.0 \mathrm{Aq} 25$ Liter) behandelt und in zwei Monaten auch hergestellt.

G. stellte die Diagnose eines multiformen Erythema exsudativam, hervorgerufen durch den Gebrauch des Brom und ist der An. sicht, das Arsen-Chinin habe viel dazu beigetragen, die Hautkrankheit zum Schwunde zu bringen, indem es frühzeitig die nervöse Centralstörung heilte.

Auspitz.

Duhring. Notes of a caso of Dermatitis herpetiformis multiform is etc. (Pliladelphia med. Times July 1884. und Journ. of the Amer. medic. Association. August 1884.)

Duhring liefert als Grundlage einer ausführlichen Monographie mohrere Krankengeschichten von "Dermatitis herpetiformis", darunter jene eimes eigenen Falles, eine 28jährige Frau betreffend, bei welcher vor 11 Jahren das Leiden im Anschlusse an die Gravidität und nach erfolgter Entbindung unter andauernden Unregelmässigkeiten in der Menstruation sich entwickelte und von da $a b$ alle möglichen Stadien der Efflorescenzbildung, als Bläschen-, Pusteln-, pemphigoide Blasen- und impetiginöse Geschwürsbildung beobachtet warden. Manchmal machte der Process für Wochen und Monate Stillstand, um nach ebenso langer Zeit wieder mit erneuerter Heftigkeit zur Erscheinung zu kommen. Die locale Application von Schwefelpräparaten und innerliche Anwendung von Eisen und Arsenik vermochten für längere Zeit Besserung herbeizufülıren.

Das Wesen der Krankheit ist angeblich ein Entzündungsprocess 
in der Haut von herpetiformem Charakter, mit ausgesprochen chronischem, zu Recidiven sehr genejgtem Verlauf, welcher unter-schweren Allgemeinsymptomen, wie Fieber, Ueblichkeiten, Kopfschmerz etc. und unter heftigem Hautjucken zum Ausbruche gelangt, dabei sowohl im Eruptionsstadium, wie im späteren Verlauf der Dermatose eine grosse Polymorphie der Efflorescenzen darbietet, wolchem Umstande der Autor auch durch die Eintheilung in Dermatitis herpetiformis erythematosa, vesiculosa, bullosa, pustulosa, papulosa und multiformis Rechnung getragen hat.

Die Krankheit erweist sich refractär gegen allo therapeutischen Massnahmen, recidivirt und exacerbirt sehr hïufig. Hochsinger.

\section{Stauungs-Dermatosen (Dermatosen mit vorwaltender passiver} Circulationsstörung A.).

Unna. Die Staungs-Dermatosen des Unterschenkels and ihre Behandlung. (Sonderabdrack d. deutsch. Medicinal-Zeitung Heft 39. 1884.)

Zuvörderst handelt es sich nach Unna bei Staunngs.Dermatosen des Unterschenkels darum, die Stauung zu beheben und sodann den jewriligen krankhaften Zustand in Behandlung zu ziehen. Durch erhöhte Lagerung der Extremitüt wird wohl die Stauung für die Zeit dieser Lagerung hintangehalten; wo man aber dieses Resultat anch ohne den Kranken an das Bett zu fessein erreichen will, nuss man zu anderen Mitteln greifen. Zu diesen gehören die circulär angelegten Binden, der Gummistrumpf und die Martin'sche Binde. Bei Neigung zu starker Transpiration oder Erythembildung wird durch die wasscrdichte elastische Binde mehr geschadet als genützt. Die Shoemaker'schen, aus Gummi und Seide hergestcllten, wohl elastischen aber transpirablen Binden sind viel zu kostspielig. U. cultivirt nun seit Jahren mit gutem Erfolge folgende Bchandlung: Nach erfolgter Einleimung des trkrankten Unterschenkels bis anf die nässende und ulceröse Stelle mit erwärmtem Zinkleim wird (ine zweiköpfig gerollte, appretirte Mullbinde in Wassér getaucht und so um die Extremität gewickelt, dass die Bindenköpfe über der nässenden und ulcerösen, nit einem entsprechenden Medicamente bedeckten Stelle sich kreuzen. Man legt den Verband so fest an, als es der Patient verträgt. 
Was die Localbehandlung der verschiedenen, in Folge der Circalationsstörung auftretenden Affectionen betrifft, entspricht diese den bekannten Grundsätzen des Autors; neben äusseren Medicamenten werden noch innerliche Mittel verabreicht. Bei den Unterschenkelgeschwïren macht $U$. wie in seinen anderen Schriften auf den Unterschied in der Behandlung; wenn es sich um Granulations-Bildung oder Ueberhäutung handelt, aufmerksam.

Horovitz.

Barduzzi. Hautleiden Diabetischer. (Gaz. degli Ospitali 1884. Giorn. ital. delle inal. ven. e della pelle. 5. 1884.)

Der Antor zählt zu den diabetischen Hautleiden die folgenden: 1. Erytheme. 2. Urticaria papulosa. 3. Furunkel. 4. Gangrän. 5. Paronychien. 6. Nekrose. 7. Hantjucken. An den Geschlechtsorganen allein: 1. Erytheme. 2. Eczeme. 3. Herpes. 4. Balanitis. 5. Pruritus. Der Aator schliesst seine Betrachtungen mit den folgenden Sätzen: El gibt eine specielle Gruppe von Hautleiden, die in Folge ihres Urspranges, ihrer Symptome, ihrer Behandlung würdig sind erneutor klinischer und chemischer Untersuchungon. Hieher gehören insbesondere jene Veränderungen, die in Folge von Diabetes am Genitalapparate sich entwickeln könnerı. Alle diese Symptome könrın einen Diabetes enthüllen, der bisher noch kein anderes symptom geztigt hatte, oder dessen andere Symptome bisher anders gedeutet worden waren. Verf. betont schliesslich, dass bei Diabetischen Hantkrankheiten beobachtet werden, welche mit dem Diabetes nichts gemein haben, als die Coincidenz, aber in Folge der den Gesammtorganismus modificirenden Erkrankung auch Veränderungen der Form und des Verlaufes erleiden, deren genaues Studium dieselben von den wirklich diabetischen Hautkrankheiten zu unterscheiden erlaubt.

Finger.

C. Pellizzari. Ulcera cutanea d'origine nervosa (? R.) (Bollettiro della Società dei cultori delle Scienze mediche. II. 1884.)

Im Docember 1883 wurde P. ein 17 Monate alter Knabe mit einem Geschwür an der Wade vorgestellt. Derselbe war cachektisch, anämisch, beide untere Gliedmassen, besonders aber die linke untere Extremität sehr abgemagert. An der Mitte der linken Wade sass ein ovales Geschwür, ınit seinem längeren Durchmesser von $3 \mathrm{Ctm}$. zur Länge der Wade quergestellt. Das Geschwür durchdrang Haut und subcutanes 
Gewebe bis auf die Muskeln. Der Grund des Geschwüres ist blass und eitrig, die Ränder gegen den Grund allmählich abfallend. Anamnestisch wurde constatirt, dass der bis dahin kräftige Knabe vor 3 Monaten an heftiger Diarrhüe erkrankte, die 30 Tage danerte. Mitte October 1883 entwickelte sich, während der Knabe in Folge der Diarrbőe sehr rasch ab\%elirte, an der linken Wade eine Blase, welche platzte, es entleerte sich blutiges Serum. Der Grund der Blase bedeckte sich mit mortificirtrm Gewebe, das immer mehr zunahm. Die elektrische Untersuchung ergab am ganzen Körper normale Verhältnisse, bis auf die linke Unterextremität, die bedeutende Herabsetzung der faradischen und galvanischen Mnskelerregbarkeit ergab. Elektrische Behandlung führte nach 14 Sitzungen zur Heilung der Wande, welche P. als Rupia escharotica (Willan-Bateman) auffasst.

Fing $\theta$.

Eichhoff. Zur Aetiologie der multiplen cachektischen Hautgangrän. (Dentsch. med. Wochenschrift Nr. 47, 1884.)

Bei durch irgend eine überstandene oder noch bestehende Krankheit cachektisch gewordenen Kindern entstehen nach E. bisweilen Ulcera. tionon der Haut in grosser Anzahl, dio bald einen gangränösen Charakter annehmen. E. beobachtete drei derartige Fiille. Der letzte Fall betraf ein $1 \frac{1}{2}$ Jahre altes Kind, welches zwei Wochen vor Ausbruch der Erkrankung Masern überstanden hatte. An der Hautdecke dieses Kindes waren zerstreut Flecken dunkeIrother Farbe, Blasen trüben Inhaltes und Grschwüre mit steilen Rändern und schmierig-speckigem Grunde zu gewahren. Einzelne Geschwüre sind mit einem trockenen schwarzen Gangränschorf bedeckt.

E. untersuchte die vom Geschwürsgrund hervorgeholten Massen unter dem Mikroskope und fand in denselven nebst Eiterkörperchen nnd. Zellẹn eine ganz bestimmte Pilzform, die der Grösse und Beschaffenheit nach mit Trichophyton tonsurans Malmsten übereinstimmte. A uffallend war die grosse Menge der Mycelien. Die Bacterien hält E. für unwesentlich in diesem Befunde, da er in dem Schimmelpilze den Krankheitserreger gefunden zu haben glaubt, der in einem geschwächten Organismus mit reducirter Zellthätigkeit diese Krankheit bewirken könne. Entsprechend dem Befund war auch die Therapie dieses Leidens. Nächst der internen Verabreichung roborirender Mittel wurde eine kräftige (?) Thymolsalicylsalbe local applicirt. Heilung nach acht Tagen.

Horovitz. 
Fournier. Rapide Gangrăn des Penis. (Semaine médicale Dec. 6, 1883.)

Der mitgetheilte Fall ist der vierte, den Fournier beobachtete. Unter Fieber und der Entwickelung einer allgemeinen Purpura der Penisdecke wird dieselbe rasch brandig and abgestossen. Eine renerische Infection war nicht nachzuweisen. F. ist geneigt, in diesem Uebel eine selbstständige Krankheitsform zu sehen. Horovitz.

Valentin. Ueber hereditäre Dermatitis bullosa und hereditäres acutes Oedem. (Berl. klin. Wochenschr. Nr. 10, 1885.)

Valentin bezeichnet als hereditäre Dermatitis bullosa eine Hautaffection, die in einer bei Bern wohnenden Familie seit wenig. stens vier Generationen erblich und bis jetzt in $11 F$ ällen constatirt ist, von denen nur zwei Frauen betrafen. Keine Generation war übersprungen und von keinor gesunden weiblichen Descendentin das Uebel auf die Nachkommen übertragen. Der intensivste, aber für Alle typische Fall betraf einen 16jährigen kräftigen Mann, dessen Haut für Stich und elektrischen Reiz normal empfindlich erschien, aber cine Urticaria factitia rubra zeigte. Im Winter fast frei von abnormen Erscheinungen, erhielt er im Sommer von jeher durch geringen, aber anhaltenden Druck (Sitzen auf Holzbänken, Druck der Strumpfbänder oder Hosenträger, Gehen, Händearbeit) reichilche Blasenbildung auf der Haut. Die Blasen, fast durchwegs ohne entzündliche Beschaffenheit der Haut, erbsen- bis wallnussgross und darüber; Inbalt k]ar, schwach gelblich, langsame, narbenlose Verheilung, nach der die Stellen immer eine Weile geröthet blieben.

Vorfasser findet einige Aelmlichkeit mit gewissen gutartigen Pemphigusformen; man müsse eine erbliche Verminderung der Resistenz grgen Traumen in den Geweben der Haut annehmen. Verf. hat auch die Erblichkeit dos von Quincke-Dinkelacker beschriebenen fliegenden acuten Oedems bestätigen können. (Die Fälle Valentin's möchten kaum als Dermatitis aufzufassen scin, sondern schliessen sich (als persistirende Form) an die Akantholysen Auspity's an: Vermindcrte Resistenz der Stachelschicht, bei geringer Läsion Austritt von Serum, mit yar keiner oder secundärer Fluxion. Die bestehende Urticaria fact. rubra zeigt, dass ausserdem angioneuritische Disposition vorhanden war. Wichtiger als die chemische Analyse des Blaseninhalts wäre die Untersuchung, ob die Blasen fächerig sind, gleich denen des 
Eczems der Pocken oder ohne Maschen, wie sie Auspitz im Pemphigus fand.)

Caspary.

Harley. Die Pathologie des Myxödems, an einem typischen Falle illustrirt. (Sitz. der Roy. med. and chir. Soc. v. 8. April 1884. Brit. med. Journ. Nr. 1216 S. 762, 19. April 1884.)

H. berichtet über die Section eines typischen Falles von Myxödem. Dieselbe ergab Adhäsionen und Verdickung der Pleura, fibröse Degeneration, einer Lunge, die thoracalen Lymphdrüsen in die dicken Pleuraschwarten eingeschlossen, Peritonitis. Daneben fielen folgende zwei Thatsachen auf: 1. Die Blutmenge war gering; obwohl das Herz contrahirt und leer, die geschrumpfte Lunge blutlos war, war doch der Blutgehalt der grossen Gefüsse und Baucheingeweide gering. 2. In allen Körperorganen fand sich eine bedentende Znnahme des Bindegewebes, ob auch der Mucingehalt vermehrt war, wagt $H$. nicht zu entscheiden. Das Nervensystem und der Sympathicus zeigten keine besonderen Veränderung n. H. sieht das Myxödem, sowie das Selerem als Krankheitsbilder an, welche durch Erkrankung der sympathischen Ganglien bedingt werden und will ihuen daher nicht einen Platz als specifische Krankheiten anweisen, sondern sie nur als Varietäten chronischen Siechthums ansehen, welche von einer Herabsetzung der vitalen Functionen abhängen und mit fibröser Degeneration besonders d'r Lungen vergesellschaftet sind, welche Verïnderung sich meist auf cine vorausgegangen $\oplus$ entzündliche Erkrankung zurückführen lässt. In der Discussion, die sich anschlirsst, macht Ord auf geistige Störungen und die auffällige Atrophie der Schilddrüse in diesen Fällen aufmerksau. Ralf betont die auffällige Blutarmuth dieser Individuen; die sich auch im Leben durch den geringen Gehalt des Urins an Harnsüure äussert. Was die Zunahme des Bindegewebes betrifft, so nehme nur die Grundsubstanz, nicht aber die Bindegewebselemente zu und diese bestehe eben vorwiegend ans Mucin. Moroch owitz habe nachgewirsen, dass beim Embryo alles Bindegewebe aus dem Collagen und Mucin stamme, es sei nun möglich, dass es sich beim Myxödem um eine retrograde Metamorphose handle, bei welcher das Bindegewebe auf den embryonalen Typus zurückkehrt. Hadden betont, dass die Veränderungen der Thyreoidea zum Krankheitsbild gehören und Harley bemerkt schliesslich, dass in seinem Falle geistige Störungen fehlten und er geneigt sei, das Hauptgewicht in seinem Falle auf Verände- 
rungen des Sympathicus zu verlegen, die durch die heftige Pleuropneumonie bedingt, lange nach Heilung derselben das Myxödem hervorriefen. (? R.)

Finger.

West. A case of myzoedema with autopsy. (Boston med. and surg. Journ. Nr. 3. p. 50, 1884. - Centralbl. f. klin. Med. Nr. 42, 1884:)

Fall von Myxỏem bei einer hereditär mit Neurosen belasteten Frau, der, sehr genau nitgetheilt, im Wesentlichen mit den bislang beobachteten Fällen übercinstimmt. Gegen Ende des Lebens traten Schluckbeschwerden auf, die Zunge war enorm geschwollen, presste überall an die Zăhne, auch das Wassertrinken war sehr erschwert. Bei Anstrengungen wurde Pat. rasch dyspnoisch, wăhrend des Schlafes wurdo Cheyne-Stoke'sches Phänomen beobachtet. Eines Nachts trat ganz plötzlich während des Schlafes der Tod ein. Eine Menge während des Lebens angestellter therapeutischer Massnahmen war ganz ohne Nutzen geblieben.

Die Autopsie wurde sehr bald nach dem Tode angestellt.

Sie ergab ausser den im Leben schon beobachteten ödematösen Veränderungen der Haut auch eine ähnliche Infiltration der Lungenschleimhant, welche zur Verengerung der Stimmritze geführt hatte und wahrscheinlich auch die Todesursache war. Gehirn normal; die Thyrcoidea wurde beim Herausnehmen so verletzt, dass ihre Grösse nicht zu bestimmen war. Ihr Aussehen bot nichts Besonderes. Notirt ist noch ein reichlichor Blutgehalt in der Milz, den Nieren und der Leber.

Meller. Beitrag zur Lehre vom Sclerema adultorum. (Inaug.Dissert. Strassbury 1884.)

In einem der beiden von Meller als Sclerem beschriebenen Fälle waren auf der allgemeinen Körperdceke auch scharf unscbriebene Stellen rother Farbe und mässiger Elevation zu gewahren. Die oberen Extremitäten waren fast symmetrisch mit den Scleremflecken bedeckt. Die mikroskopische Untersuchnng excidirter Stellen ergab Abflachung der Papillen und Rundzelleninfiltrate längs der Gefässe im dichtmaschigen Cutisgewrbe. Patient, ein 67 Jahre alter Greis, starb ausserhalb des Spitäles.

In zweiten Falle handelte es sich um ein universelles Sclerem bei einem 49 Jahre alten Manne. Am stärksten ausgeprägt war die 
Affection auf den Vorderarmen und Händen. In beiden Fïllen war die Hautempfindlichkejt unverändert; im zweiten Falle die Schweisssecretion verringert.

Àspitz.

Neuritische (durch Erkrankung sensiblar Nervenelemente bedingte) Dermatosen und Idioneurosen der Haut.

Pozze. Trophische Störungen bei tranmatischer, peripherer Neuritis. (Gaz. médic. de Paris 14. Oct. 1883.)

Ein 50jähriger Mann stürzte auf den rechten Ellbogen and zog sich eine Luxation dieses Gelenkes zu. Unmittelbar nach dem Trauma heftige Schmerzen im kleinen and Ringfinger, sofortige Lälumung einiger Muske]n des Vorderarmes. Im weiteren Verlaufe Schmerzen in der Hand und im Vorderarme ohne namhafte Sensibilitätsstörung. Zur Zeit der Aufnahme ins Spital bestand bereits Lähmung im Bereich aller Aeste des rechten Plexus brachialis, Atrophie der Maskeln selbst am Oberarm mit Veränderung der elektrischen Erregbarkeit.

Die Haut des erkrankten Gliedes war verdünnt und glatter als die des anderen Armes, die Nägel eigenthümlich verstärkt, die Temperatur in der Hohlhand um $1^{\circ} \mathrm{C}$. gesteigert. Die gelähmte Hand selbst war der Sitz einer reichlichen Epithel-Desquamation, welche unverkennbar die Folge von Bläschenbildung mit Ruptur derselben war. Eigenthümlicher Weise trat Bläschenbildung mit nachfolgender Desquamation auch auf der linken nicht afficirten Hand in ganz symmetrischer Weise auf.

Freud - Wien.

Scarenzio. Ueber einige Krankheiten, welche darch nervöse Reflexaction erzengt werden. (Ann. univ. die Medic. 1884. Giorn. Ital. delle mal. ven. e della pelle 2. 1884.

Dass die Haut in Folge ron nervösen Reflexactionen erkranken kann, ist eine bekannte Thatsache. Diese Veränderung der Haut kaun sich nach Sc. äussern entweder in einfachen Kreislaufstörungen in den Capillaren, oder in materiellen Veränderungen.

Sc. wirft nun die Frage auf, ob es eine Nervonleitang gebe, seien es nun die Vasomotoren selbst oder von diesen verschiedene Nerven, welche peripher einen Eindruck empfangen, zam Gentrum and von hier wieder nach der Peripherie leiten und an der peripheren Stelle eine trophische Störung bewirken können. Um dies za beweisen, muss die 
irritirende Ursache anșserhalb des Organismus srin, auf eine Partie, wolche solche Nerven besitzt, einwirken, diese Wirkung zum Centrum und durch specielle Nerven nach der Peripherie geleitet werden und so eine Veränderung der Haut erzeugen, welche in dem Augenblick, als dic Ursache schwindet, auch nachlässt. Fr führt nun einige Fälle an, welche diesen Bedingungen entsprechen:

1. Ein 42jähriger Mann litt seit einigen Monaten an einem läst:gen, ausgedehnten Hautjucken mit Aufspringen von Knötchen auch an Stellen, an denen er nicht kratrte. Der Kranke litt an Taenia und mit Entfernung des lasstigen Gastes schwanden auch dio Hautsymptome.

2. Auch in einem zweiten Falle schwanden älnliche Symptome nach Beseitigung einer Taenia.

3. In einem dritten Fallo wurden diese Symptomedurch Oxyuris bedingt und durch Abtreibung derselben beseitigt. - Sc. schliesst daraus, dass:

1. Eine einfache Reizung einer Stelle, wilche von Vasomotoren oder trophischen Nerven versorgt wird, durch diese nach dem Centrum geleitet werden kann, von woher sie Nervenfasern gleicher Dignität nach der Peripherie weiterbringran und eine trophische Erkran. kung der Haut bedingen.

2. Dies spricht für einen wirklich speciellen trophischen Apparat, der von den Ganglien unabhängig ist.

3. Die Fasern dieses Apparates wirken in diesem Fall einfach als Leiter, was nicht hindert, dass sie, wenn sie oder ibre Ganglion materiell erkranken, trophische Hautkrankheiten bedingen.

\section{Finger.}

Fr. Stabell. Herpes zoster bilateralis. (Tijdskrift for praktisk Medicin, Nr. 13, 1884.)

Eine 18jährige Fabriksarbeiterin stellte sich am 21. März 1884 mit einem Herpes zoster vor, der sich vom 4.-6. Brustwirbel um die linke Thoraxhälfte herum verbreitete. Die Eruption war sehr heftig, die Bläschen sehr dichtstehend und in der Mitte der angegriffenen Hautpartien vollständig confluirend. Die Eruption entsprach der Ausbreitung des 4. und 5. Intercostalnerven. Am 27. März stellte sie sich wieder vor, jetzt auch mit einem rechtsseitigen Zoster, der aber vom ersten Lendenwirbel ansgehend um die rechte Hälfte des Unterleibes herum in schräger Linie sich zu der Symphysis pubis hinstreckte, also 
der Verbreilung des $\mathrm{N}$. iliohypogastricus und ilioinguinalis rntsprechend. Sowohl in den links wie rechts afficirten Hautbezirken war eine hochyradige Anästhesie vorhanden, die ganze Dicke der Haut konnte mit einer Nadel durchstochen. werden, ohne dass die Pationtin es bemerkte.

Boeck.

Pitrès and Vaillard. Beitrãge zur Kenntniss der peripheren, nicht tranmatischen Nouritiden. (Arch. do Neurologie Nr. 14, 15 und 17, 1883.)

Aus der vorliegenden interessanten Studie, welche ausführlich dic histologischen Veränderungen der bei peripherer Neuritis degenerirten Nerven und die begleitenden Erkrankungen der Haut behandelt, seien zwei Beobachtungen mit anatomischer Untersuchung hervorgehoben: 1. Bei einer 30jährigen, an rechtsseitiger Pleuropneumonie verstorbenen Frau fanden sich die Narben eines Herpes Zoster im rechten sechsten Intercostalraum und frischer Zostereruption im elften Intercostalraum derselbrn Seite. Der sechste Intercostalnerv war im Zustande hochgradiger Degeneration; welche sich durch das Spinalganglion in die hintere Wurzel fortsetzte. Die Zellen des Spinalganglions anscheinend unverändert, im entsprechenden Rüekenmarksabschnitt keine Veränderung (wolcher Befund schlecht zu den herrschenden Anschauungen über die Bedeutung der Spinalganglienzellen für die Integrität der hinteren Worzel stimmt, wenn der bistologische Befund nicht etwa eine andere Auffassung zulässt. R.). 2. Bei einem Tabiker hatte sich Mal perforant in der planta pedis auf der einen Seite vor allen tabischen Symptonen auf der anderen einige Monate nach der ersten Manifestation der Tabes entwickelt. Bei der mikroskopischen Untersuchung zeigten sich insbesondere beide N. plantares interni entartet. Freud - Wien.

Deghilage. Trigeminnsueuralgie varbanden mit trophischen Störungen. (Archives méd. belges. April 1884. - Centralbl. für klin. Med. Nr. 40, 1884.)

Entwicklung einer circumseripten Alopecie im Anschluss an eine Trigeminusneuralgie. Pat., ein Soldat, zeigte schon vorher eine circumseripte Alopecie der linken Seite, dicht oberhalb der Stirn, von der Grösse zweier Fünffrancstücke, angeblich im Verlaufe von "Kopfschmerzen" entstanden.,Während. seines Aufenthaltes im Lazareth, in welches er als Reconvalescent wegen einer unklaren Brustaffection 
aufgenommen, wurde er von einer Trigeminusneuralgie der rechten Seite mit äusserst heftigen nächtlichen Schmerzparoxysmen befallen. Es stellten sich entsprechend den seitlichen und hinteren Partirn der rechten Kopfhälfte leicht geschwollene und geröthete, auf Druck schmerzhafte Plaques ein, in deren Bezirk innerhalb der dreiwöchentlichen Dauer der Affection die Haare völlig ausfielen.

Riehl. Hyperidrosis unilateralis. (Wiener medicinische Presse Nr. 34, 1884.)

Der Fall betraf eine 41jährige Frau, die am 4. November 1884 von Carl v. Braun wegen Carcinoma ateri operirt und am 28. Nov. behufs leichterer Reinhaltung in das permanente Bad der dermatol. Klinik gebracht wurde. Die Untersuchung ergab eine thalergrosse granulirende Wunde an der Stelle der Vaginalportion, leichten Bronchialkatarrh beider Lungen, Druckempfindlichkeit der Unterbauchgegend, sonst normale Verhältnisse. Pat. klagte, dass sie seit Jahren an linksseitigen Kopfschmerzen leide, die in unregelmässigen Intervallen wiederkehren und mit Röthung, Hitžgefühl und Scliweiss an der linken Kopfseite verbunden seien. Am 28. Norember meldete sich ein Anfill und konnte damals folgender Befund constatirt werden: Röthung der linken Gesichtshälfte, Temperaturerhöhang daselbst bei sonst intactem Tastgefühl und ein gewisses unangenehmes Gefühl selbst auf leichte änssere Reize. Soweit die Röthung reichte, war Schweiss in thauper. lenähnlichen Tropfen zu sehen, dessen Reaction saner war. Linke Pupille erweitert, beide Conjunctiven etwas geröthet. Der Anfall daucrt 36 Stunden. Frühere Anfälle waren mit Brechriz nnd wirklichem Erbrechen verbunden. Am 4. December trat der letale Ausgang ein. Peritonitis und Herzerfettang. Das Ganglion sup. sin. des Sympathicus vergrōssert, stärker injicirt und gerōthet. Der ganze Querschnitt des Ganglion erwies sich bei der mikroskopischen Untersuchung von Rundzellen durchsetzt. Die Gefässe stark mit Blut gefüllt, die einzelnen Venen unrcgelmässig ausgebuchtet. Eine Gruppe von Gangliı!zellen war geschrumpft, stellenweise war auch ein Bluterguss zwischell den Ganglienzellen und den Kapseln derselben zu sehen. Die Rundzelleninfiltration war auf der ganzen Länge des Ganglion zu constatiren, die Nervenfasern waren unverändert.

Riehl sieht in den klin. Erscheinungen die Folge der Reizung sympathiseher Fasern.

Horovit\%. 
Le Page. Plica neuropathica. (Brit. med. Journ. 26. Juni 1884.)

Bei der Plica neuropathica soll im Gegensatz zur „pnlonica" (? R.) die Kopfhaut intact sein, weder Haare noch Follikel bieten Veränderungen dar und die Verflechtung ist keine regellose, sondern in gewissem Sinn symmetrische. Verf. berichtet über folgenden Fall: J. K., ein 17jähriges Mädchen, besuchte ihn am 30. September 1882; das schlecht genährte, bleichsüchtige Mädchen klagte, sie hätte seit etwa einer Woche allgemeine Schwïche und Betïubung, dabei stechende und reissende Kopfschmerzen gefühlt. In der Hoffıung sich Linderung zu verschaffen, nahm sie am 29. Septembor ein warmes Bad, nach welchem sie in Gegenwart ihrer Eltern die Haare trocknete und kämmte. Während sie so auf der linken Kopfseito beschäftigt war, fühlte sie auf der rechten Kopfhälfte einen Schmerz, als $v \mathrm{~b}$ ihr die Haare ausgerissen würden und als sie hinfühlte, fand sie angeblich ihr ganzes, 5 langes Haar in einen Knoten zusammengerollt, den zu entwirren ihre Eltern sich vergebens bemühten. Die Untersuchung ergab: die Haare der linken Kopfbälfte glatt, leicht gerollt, geschmeidig, die der rechten von der Mittellinie an in einen Klumpen geballt, unter dessen oberster Schichte sich deutliche Anordnung in Wirbeln und Schleifen erkennen liess. Die Kopfhaut intact, die mikroskopische Untersuchung ergab, dass die Haare verschieden geformte Querschnitte darboten, die geringelten runde, die in Schleifen gelegten platte Qu+rschnitte hatten. Der Verf. ist nun bemüht, die derVerkneuelung der Haare vorausgehenden Erscheinungen, das Reissen und Zucken, als Krampf der Arrectores pili zu deuten und daraus die Verkneuelung zu erklären, indem er, obwohl das Mädchen hysterisch, doch eine mechanische Ursach aus den Anraben derselben nnd der Eltern ausschliesst. (Auch eine absichtliche Täuschung? R.) Finger.

Behrend. Zwei Fälle von Prurigo nach Scharlach; ein Beitrag zur Aetiologie der Prurigo. (Deutsche med. Wochenschrift Nr. 25, 1884.)

Behrend glaubt in zwei Fallen das Auftreten von Prurigo in Folge überstandenen Scharlachs sicher annehmen zu können. Dabei ist hervorzuheben, dass beide Male nach erfolgter Desquamation eine Pusteleruption auftrat, welche auch die palma manus und planta pedis nicht verschonte und auf die dann im 4 . und 5 . Lobensjallre die typische (? R.) Prurigo folgte. B. weist noch auf die an die Vaccination 
sich anschliessenden Impfausschläge acuter Natur hin, welche .meist mit dem Abtrocknen der Vaccinepusteln verschwinden, manchmal aber doch selbststãndig chronisch weiterbestehen. Man müsse daher annehmen, dass bei vorhandener Disposition der Haut za irgend einer Erkrankung unter dem Einflusse eines im Blute circulirenden Giftes bald diese bald jene Fantaffection anfureten könne; in den obangeführton Fällen Prurigo unter dem Einflusse van Scharlachgift. (?).

Auspitz.

\section{Epidermidosen (Wachsthums-Anomalien der Hant von epithelialem} Ursprung und Typus A.).

Hilbert. Partielle Hypertrichosis neben angeborener Ich. thyosis circumscripta. (Virchow's Arch. Bd. 99. Heft 3. 1884.)

Hilbert fand bei ciner jungen, gesunden Dame - gegenüber dem sonstigen Sitze congenitaler partinller Hypertrichose am Rampfe - diese Affection an einer Extremität, gepant mit ganz circumscripter Ichthy osis. Die abnorme, gleichmässige, ziemlich dichte Bohaarung betraf dje linke Schulter nnd den linken Arm bis zur Höhe des Processus styloideus radii; die Hand war normal. Die cinzelnen Haare, etwa $1 \mathrm{Ctm}$. lang, ziemlich dick, wie borstenartig an\%nfühlen; die Farbe nicht rüthlich wie die des Haupthaares, sondern braun; die Haut darunter lichtbraun pigmentirt gegenüber der hellen Färbung der übrigen Hant, sonst normal. Inmitten, über der Spina scapulae, eine harfreie, dunkelbraune, durch zahlreicho Risse in poJygonale Folder gotheilto Stelle (Ichthyosis simplex). Caspary.

Amicis. Ueber einen seltenon Fall von Hystricismas mit universeller Seborrhüe. (Giorn. ital. delle mal. ven. e della pelle 6, 1884.)

Am 7. Jänner 1884 wurde ein 55jähriger gesunder Manm mit änsserst seltenen Veränderungen der äusseren Haut aufgenommen. Die Eltern des Mannes waren gesund and starben in hohem Alter. Niemand in seiner Familie leidet an einer Hantkrankheit. Seine Erkrankung begann im zweiten Lebensjahre, indem sich auf der Haut zunächst Flecke von rother Farbe, rundlicher Form und unregelmässiger Begrenzung bildeten, die über den Körper zerstrent waren, nach mehrmonatlichem Bestande eine mehr braune Farbe annahmen, sich 
mit Hornprodukten derselben Farbe bedeckten. Beim Ablösen der letzteren, das von heftigen Schmerzen begleitet war, blieb eine rauhe Oberfläche zurück, welche kleine, kaum stecknadelkopfgrosse papilläre Excrescenzen zeigte, die beim Abschneiden bluteten. Die Horngebilde wuchsen and wenn sie ihro grösste Entwicklung erreichten, lockerte sich ihr Zusammenhang, sie fielen ab and wurden durch neve ersetzt. Ausser stellenweisem Jucken empfand Pat. keine abnormen Sensationen. Dis Untersuchung des kräftigen Mannes zeigt den Hals, den Rücken, mit Ausnahme zweier Flecke über den Lenden, umschriebene Stellen von Brast und Bauch, die oberen und unteren Extremitäten, Handund Fussrücken, mit vollständiger Freilassung der Gelenksbeugen, des Genitale, After, der Interdigitalspatien, mit Horngebilden von braner Farbe bedeckt, welche, an den peripheren Körperpartien am höchsten, gegen den Rumpf zu abnehmen, prismatische oder cylindrische Form, eine geriffte Oberfläche und polyedrischen Durchschnitt haben, rund oder oval gestaltet sind, der Haut senkrecht und nur an Hand- und Fussrücken alle im gleichen Sinne schief aufsitzen sowohl am Halse als an der Brust vorwiegend von Ansammlung sebumartiger Massen gebildet, durch Kratzen Iricht zu zerstören sind; fettiges Gefühl und eine rothe hyperämische Hautstelle hinterlassen. Sensibilität auch an den verhornten Stellen intact, Schweiss- and Talgsecretion vermehrt.

Die mikroskopische Untersuchung einer von dicken Hornauflagerungen bedeckten Partie ergibt: Vergrösscrung und Ver]ängerung der Papillen, die Blutgefässe der Papillen und des Stratum reticulatum sehr weit. Arrectores pilorum- sehr ausgebildet, die Talgdrüsen vergrössert, viellappig, die Ausfülırungsgänge erweitert, mit Talgmaşsen erfüllt, die Schweissdrüsen erhalten. Das Rete Malpiglii, sehr verbreitert, schickt zwischen die Papillen oft verzweigte Auslïufer ans. Das Str. granulosum verdickt, aus 3-4 Reịhen Eleidin führender Zellen gebildet, die Hornschichte immens entwickelt, die Zellen in den tie. feren Reihen compact, llach oben zu mehr locker angeordnet, haben Zwischenräume; auf Querschnitten erscheinen sie dentlich concentrisch geschichtet, zu ovalen und rhombischen Figuren angeordnet.

Die chemische Untersuchung ergab über $70 \%$ Keratin.

Als das Primăre des ganzen Processes betrachtet der Autor die Vergrösserung des Str. epitheliale, welches mit seinen Auswüchsen tief zwischen die Papillen eindringt, wobei aber die Vergrösserung der Papillen selbst so bedeutend ist, dass die Tendenz zum vermehrten 
Wachsthum gleichmässig Epithel, Papillen, Bindegewebe getroffen za haben scheint. Die Verbreiterang des Str. granulosum und dessen vermehrter Eleidingehalt sind ein dentliches Zeichen des lebhaften Verhornungsprocesses, wie ja anch die chemische Untersuchung bedeutende. Mengen Keratin nachgewiesen hat.

Die Veränderung der Talgdrüsen gehöre nicht unbedingt znm Process der Ichthyosis histrix, so dass man unsern Fall speciell als Ichthyosis sebacea bezeichnen könne, da diese Processe nicht als Stadien derselben Erkrankung, sondern als eigene Errährungsstörungen anzusehen seien, während die Ichthyosis histrix den als Naevi verrucosi, Papillomatosis catis neuropathica bezeichneten Processen näher stehe.

Finger.

Blair. Erfolgreiche Behandlang eines Naevus mit ortlicher Application von Arsenik. (Brit. med. Journ. Nr. 1226. S. 762, 19. April 1884.)

Dem Verf. wurde die Bohandlang eines $N$ aevus übergeben, der auf dem behaarten Kopfe selhr ausgebreitet über der vorderen Fontanelle lag. Nachdem die Inipfung anf demselben von der Mutter des Kindes verweigert wurde, wandte der Vf. den von Beatty empfohlenen Liquor arsenicalis mit dem Erfolge an, dass Pat. in siebon Wochen vollständig geheilt wurde, ohne während dieser Zeit an besonderen Schmerıen zu leiden, ausgenommen wenige Tage, als der Naevos ulcerirte. Zweimal wurde die Behandlung durch gastrische Erscheinungen unterbrochen, die stets nach zwei bis drei Tagen schwanden und nach der Ansicht des Vf. durch Resorption des Mittels bedingt wurden.

Finger.

Mackenzie. Zwei Fälle von Lichen planas, in donen die Eraption entlang dem Verlanf der Nerven angeordnet war, mit Bemerkungen über den Einfluss des Nervensystemes a f die Vertheilung ron Hautkrankheiten. (Harveian Soc. of London 1884. 16. Octob. Brit. med. Journ. 1884. 29. Nov.)

Der Antor berichtet über zwei Fälle von Lichen planus, in deren einem bei einem Weibe die ersten Efflorescenzen in Form eines Halbgürtels am Rücken und Bauch, ähnlich wie bei Herpes zoster angeordnet waren und es erst später zu universeller Ausbreitung kam; während in dem zweiten Falle, auch bei einem Weibe, die ersten 
Efflorescenzen die Innenflächo des Armes, entsprechend dem Verlauf des $\mathrm{N}$. cutaneus brachii internus und ulnaris einnahmen. Im Anschluse daran bespricht der Vf. die anderen Formen von Hautkrankheiten, die nach dem Verlauf der Nerven auftreten, demonstrirt Präparate von Spinalganglicm bei Herpes zoster und kommt zum Schlusse, dass nicht nur Erkrankungen der Nerren für das symmetrische $\Lambda$ uftreten von Hautkrankheiten verantwortlich gemacht werden kōnnen, sondern auch die Gloichmässigkeit der ortlichen Verhältnisse an symme. trischen Hautstellen eino Rolle spielt, andersoits anch asymmetrisch auftretende Erkrankungen ganz wohl von peripheren nervōsen Störungen abhängen können.

Finger.

Gamberini. La dermite sfogliativa universale, quale trasformaziono del psoriasi. (Giornale internazionale dello Scienze mediche VI. 1884.)

C. G. aus gesunder Fanilie, wurde wegen Psoriasis vulgaris seit Mai 1878 wiederholt auf der Klinik G's in Bologna behandelt, das letztemal im Februar 1884. Juni und Juli 1884 kommt ein neuer Nachschab der Hanterkrankung, diesmal aber mit wesentlich anderen Symptomen zu Stande. Bimen w/nigen Tagen entwickelt sich unter heftigem Jucken eine intensive, gl ichförmige Röthang und Schwellung der Haut des Rückens, dieselbe bleibt nur kur\%e Zeit auf den Rücken localisirt, goht dann auf die Brust, die Extremitäten über, so dass schliesslich nur Handteller, Fusssohlen und Nägel intact bleiben. Während die später befallenen Stellen gleichmässig roth sind, bedecken sich die ersterkrankten mit zarten, weissen Schuppen, und mit schmerzhaften, bei Drack Ieicht blutenden Rlagaden. Natron salicylicum innerlich und protrahirte Bäder bringen ausugehend vom Gesicht, $\mathrm{Ab}$ blassen der Haut hervor, anf der die früher verdrängton Psoriasis. plaques nun wieder zum Vorschein kommen. G. fasst die Erkrankung als eine Dermatitis exfoliativa (Pityriasis rubra Hebra) auf und bespricht die Literatur und Prognose derselben, welche letztere er nicht als absolnt funest ansieht, wie er sich auch das Zustandekommen der Dermatitis exfoliativa durch verschiedene auf die Hant einwirkende Reize erklärt.

Finger.

Kingsbury. Pityriasis rubra. (Manchester Med. Soc. 19. März 1884. Brit. med. Journ. Nr. 1217. s. 818. 26. April 1884.) 
Der Pat., über den K. referirt, 25 Jahre alt, war, als ihn K. das erstemal sah, seit drei Monaten krank, er erschien sehr abgezehrt, lag vollkommen hilf- und bewegungslos im Bett, da ihm jede Bewegung, jedes Berülıren, selbst der Druck der Bettdecke heftige Schmerzen verursachte. Die ganze Haut, vom Kopf bis za den Sohlen, war intensiv roth, hie und da befanden sich auf derselben lockere Schuppen von verschiedener Dicke, uneben bis thalergross. Dio Menge der Schuppen war so bedeutend, dass ein Eimer mit den Schuppenmassen, die in Verlaufe einer Woche aus dem Bett gekehrt wurden, voljgefüllt wurde. Die Nägel erschienen verdickt, dunkel, uneben. Dic einander zugekehrten Flächen der Zehen nässten. Jucken war keines vorhanden, die Temperatur normal, der Pals schwach, der Urin enthielt Eiweiss. Der Appetit lag ganz darnieder, die Haut verbreitete einen sehr üblen Geruch. Verschiedene Mittel, darunter auch Arsenik, waren früher berrits angewendet worden. Consequente Behandlung mit Theersalben durch zwei Monate, der innerliche Gebrauch von Chinin und Eisen, kurzer Landaufenthalt stellten den Pat. (für einige Zeit? R.) lier.

Hobra hat dic Pityriasis rubra für nnheilbar erklärt, doch schon Finny und Liveing liaben Fälle von Heilung mitgetheilt. Als charakteristisch für die Diagnose sieht Vf. an: 1. die universelle Ausbrcitung, 2. die grosse Schuppenmenge, 3. die hochgradige Röthe and Empfindlichkeit der Hant, 4. die "Irockenheit derselben. Finger.

Schwimmer. Zur Diagnostik der Pityriasis rubra universalis. (Orvosi Hetilap 15. 1884. Sonderabdruck.)

Nach Erörterung der Geschichte dieser Krankheit hebt Schw. zur Symptomatologie drei Punkte hervor:-1. Das Jucken, 2. die seröse Ausschwitzung and 3. den Ausgang. Während eine Reihe von Bobachtern das Jucken in Abrede stellt, wollen andere es beobachtet haben; ebenso stehe es mit dem zweiten und dritten Punkte. Denn während viele Beobachter constant eine trockene Haut im Verlaufe dieser Krankheit gesehen zu haben meinen, haben andere auch Nässen betrachtet, und endlich hat man neben letalen Ausgängen auch Genesung constatiren können. Der eine der Sch.'schen Fälle hat Jucken und Nässen dargeboten, Exitus letalis trat ebenfalls ein; der zweite Fall verlief ohne Jucken, ohne Nässen und blieb in einem Zustande wesentlicher Besserung innerhalb der ersten sechs Monate. 
Sch. schliesst nun aus diesen Thatsachen auf rine zweifache Form der P. r. u., auf eine milde und eine schwere; ferner hält er es geboten, einzelne ungewöhnliche Complicationen in den Rahmen des Krankheitsbildes aufzunehınen und bezüglich der Ursache noch das Verhalten der Centralorgaue zu erforschen. Horovitz.

Fürst. Hypertrichosis universalis mit Hypertrophie der Kiefer-Alveolarränder. (Virchow's Arch. Bd. 96, H. 3. 1884.)

Fürst beschreibt einen ziemlich hocligradigen Fall von Hypertrichosis universalis bei einem 6jăhrigen Mädehen, deren abnorme Belaarung schon in den ersten Lebenswochen hervorgetreten, nunmehr ihren Höhepunkt erreicht zu haben schien. Theile des Gesichts, besonders aber Rücken und Strockseiten der Extremitäten zeigten cine dichte, brünette, die Hant fast verdeckende Hülle stark entwickelter Haare. Zugleich bestand - im Gegensatze zu der sonst mit Hypertrichosis universalis häufig verbundenen defecten Zahubildung - eine Hypertrophie der K i f $\mathrm{fer-Alveolarränder} \mathrm{mit} \mathrm{vollzăhligen,} \mathrm{durch} \mathrm{die}$ Vergrösserung des Alveolarbogens, sowie dureh dazwischen gewuchertes Zahnfleisch auseinandergedrängten Milchzälmen. Der Fall erinnert an Julial Pastrana, dic mit der Hypertrichosis eine echte Kieferlyppertrophie, combinirt mit unregclmässiger, aber überzihliger Zahnbildung verband.

Caspary.

Wolfberg. Zur Aetiologie der Trichorrhexis nodosa. (Deutsche medizin. Wochensehrift Nr. 31, 1884.)

W. bcobachtete an seinen eigenon Barthaaren Veränderungen, wie sie dem makroskopischen Bildo der Trichorrhexis nodosa entsprechen, and der mikroskopische Befund bestätigte die geweblichen Veränderungen, welche frühere Beobachter als charakteristisch angegeben haben. W. theilt nun mit, dass wiederholte Misshandlung dickerer Barthaare bei vielen Personen die Krankheit hervorrufen könne, und ex habe soeben dieselbe an einer Backenbartseite an sich selbst provocirt.

Die Gründe für die mechanische Aetiologie dieser Affection sind: Erstens: Der anatomische Befund, da die Haare ausserlalb der Knötchen sich wie gesunde verhalten, und die Annahme der meisten Autoren, dass die Auffaserung von inmen nach aussen entstehe, durch gar nichts bewiesen wird.

Zwcitens: Die Localisation. Das Vorkommen des Uebels an den 
dicken, markhaltigen Barthaaren spricht ebenfalls mehr für eine mechan. Entstehungsweise, besonders wenn man noch erwägt, dass das Rciben der Barthaare durch die harte knöcherne Unterlage erleichtert wird.

Drittens: Sind die bisherigen Erklärungsversuche unzureichend, weil sie einestheils sich auf nicht constante Befunde, sodann aber auf Charakteristica beziehen, welche auch bei gesunden Haaren anzutreffen sind.

Endlich spreche das Fehlschlagen der gangbaren Therapie (Salben and Waschungen) gegen die Anschauung der Autoren. Horovitz.

Mackey. Seborrhoea sebacea. Brighton and Sussex medico-chir. Soc. 2. Octob. 1884. (Brit. med. Journ. 11. Octob. 1884.)

M. stellte einen 16jährigen Jüngling vor, der an den Oberarmen und Oberschenkeln schwarze Schuppenlager zeigt, die in Abstossung begriffen sind und unter denen die Haut gesund erscheint. Ausser an den Füssen schwitzt die Haut des Pat. nirgends. Der Bruder des Pat. leidet an einer leichten Form von Xoroderma universale und schwitzt blos am Kopf. Bei beiden Pat. trat die Erkrankung nicht in der Kindhcit, sondern erst vor zwci Jahren auf.

Finger.

Roger. Acne-Keloid. Patholog. Soc. of London. Sitz. vom 1. April 1884. (Brit. med. Jomrn. Nr. 1214, S. 667, 5. April 1884.)

R. reigte die Photographie eines 53jährigen gesunden Weibes mit einem 6" langen 2 "breiten Keloid am Nacken an der Haargrenze; das. selbe hatte eine glatte, glänzende, röthliche Oberfläche mit folliculären Depressionen, aus welchen Haarstümpfe herrorragten. Bei Druck erwies sich die Geschwulst ziemlich fest und drang eine käsige Masse ans den Follikeln hervor. Die Geschwulst war ohne bekannte Ursache vor fünf Jahren als kleine Papel entstaiden. Bepinselungen mit Jodcollodium brachten Verkleinerung hervor. Die mikroskopiscine Untersuchung eines excidirten Stückchens ergab nengebildetes Bindegewebe and weite Gefässe in den tieferen Partien des Corium, jedoch ohne kleinzellige Infiltrate. Die Epidermis und der Papillarkörper erhalten, doch fehlen bis auf wenige den Haaren zugebörige Talgdrüsen alle drüsigen Adnexe. R. sieht die Erkrankung als ein wahres Keloid von Alibert an zum Unterschiede von Kaposi's Dermatosis papillomatosa capillitii, die auf entzündlicher Basis entstehe.

Finger. 
Balzer und Barthélemy. Beitrag zum Studium der gefürbten Schweisse. (Annal. de dermat. et syphil. Nr. 6. 1884.)

Bei Leuten mit profusen. Schweissen gelang es den Autoren, in der rothen Scheide der Achselhöhlenhaare Mikrococcen in Zoogloeahaufen nachzuweisen. An den Grenzen der Haufen sind die Coccen nicht immer gefärbt; es gelang ihnen ferner, das Eindringen der Coccen in das Innere des Haares nachzuweisen; ebenso begegnete man den Parasiten in den oberflächlichen Hautschichten.

Bis auf leichtes Jucken and schwache Röthung der Haut ist keine krankhafte Veränderung zu constatiren.

Horovitz.

Crocker. Drei Fälle von Xeroderma pigmentosum. Sitzung der Royal med, and chir. Soc. 25. März 1884. (Brit. med. Journ. Nr. 1213, 29. März 1884.)

Der Vortragende stellte drei Fälle dieser Erkrankung vor (die ersten, die bisher in England bekannt worden seien) and zwei Schwestern von 12 und 10 Jahren und deren 8jährigen Bruder betreffen. Ausser diesen seien bisher noch 31 Fälle bekannt, die alle ein gemeinsames Krankheitsbild darbieten. Die Erkrankung beginnt im ersten oder zweiten Lebensjahr ohno eigentliche Veranlassang an den frei getragenen Stellen von Gesicht, Nacken, Extremitäten. Zunächst entwickeln sich rothe Flecke, welche schwinden und linsengrosse Pigmentflecke hinterlassen, oder es entwickeln sich direct Pigmentirungen, die viel Aehnlichkeit mit Sommersprossen haben und an Intensität der Färbung und Grösse zunehnen. Hierauf wird die Haut trocken und atrophische Stellen treten zwischen den Pigmentirangen auf, welche letztere zu grossen Flecken zusammenfliessen. Die Haut schuppt in dünnen Lamellen und wird immer mehr pergamentartig. Einige Jahre nach dem Beginn treten oberflächliche Ulcerationen auf, welche mit Krusten bedeckt sind, während manche von den Pigmentflecken ein warziges Aussehen bekommen. Diese beiden werden in der dritten Periode endlich in wuchernde Epitheliome umgewandelt. Die Pat. werden marastisch und gehen so oder durch Metastasenbildung zu Grunde, was meist noch vor Eintritt der Pubertät erfolgt. Dem Geschlecht nach ist dio Zahl der bekannten Fälle gleich, doch werden in derselben Familie meist nur Gleichgeschlechtige befallen, so in einer 7 Knaben, in einer anderen 5 Mädchen.

Es knüpft sich an den Vortrag eine Discussion, an der Baker 
und Colcott Fox theilnchmen, die den Namen Xeroderma dureh Atrophoderma (?) ersetzt wissen wollen.

Finger.

Colcott Fox. On Urticaria pigmentosa or Xanthelasmoidea. (Sonderabdruck. London 1884.)

Der Autor bringt die Krankengeschichte eines Falles von Urticaria pigmentosa und lässt darauf eine Zusammenstellung säıntlicher bisher publicirter Fälle dieser Krankheitsform (19 an der Zahl) folgen, ans deren Beschreibungen hervorgaht, dass die hier citirto Affection immer unter den Bilde cincr gewöhnlichen Urticaria begiune, dass aber die Hyperämie und der Entzündungshof der Quaddeln längere Zeit persistiren, worauf die Efflorescenzen schrumpfen und sich in erbsengrosse Papeln und Knoten umwandeln, dio einen gelblichbraunen, bei Druck nicht verschwindenden Farbenteint gewinnen. Hauptsächlich befällt das Leiden Kinder, doch ist bis jetzt noch in keinem einzigen Falle - trot\% melrr als 10jähriger Beobachtungszeit - ein vollständiges Verschwinden der Dermatose constatirt worden. Das Mikroskop zeige, dass der Hauptsitz der Erkrankung in der obersten Schichte des Coriums zu finden sei, und dass in dem infiltrirten Maschenwerke der Papillon gelbbraunes Pigment in dichten Zügen und Haufen abgelagert werde, welches Verf. als Residuum der chemaligon erythematös-himorrhagischen Entzündung ansioht.

Hochsinger.

Eichhoff. Mittheilung eines Falles von Xanthelinma planum et tuberosum multiplex. (Deutsche medicinische Wochensch. Nr. 4. 1884.)

Eichhoff theilt einen Fall von Xanthelasma mit, der durch scin frühes Auftreten und durch die Aetiologie interessant ist.

Ein Kind von $1 \%$, Jalren, welches mit ganz glatter und gosunder Haut zur Welt kam und seit seimem zweiten Lebensmonato an "Leberflecken" litt, zeigte auf der Haut dos ganzen Körpers, besonders am Rücken und auf den Extremitäten, fernor auf der behaartelı Kopf haut unzählbare Flecken und Knötchen, sowie über das Hautniveau erhabene Flächen von strohgelber bis hellbrauner Farbe.

Der mikroskopische Befund war: Starke Pigmentirung des Rete Malpighịi und Bindegewebszellenbildung, theils normale, theils trübgeschwellte und fettig degenerirte Zellen in der Ungebung der Gefässe and Schweissdrüsen. An den Talgdrüsen fand $\mathrm{E}$. nichts $\Lambda$ bnormes. 
E. schliesst sich daher der Ansicht an, dass das Xanthelasma eine bindegewebige Neubildung sei. Vón Pilzen konnte Vf. nichts sehen. - Die Aetiologie war in der Heredität begründet. Der Urgrossvater (Vater der Mutter des Vaters) war auf Brust, Armen und Rücken mit Xanthelasma - Eruptionen behaftet. Dio Mutter des Kindes hat eine auffallend dunkle Hautfarbe, sowie einige Naevi. Dirjenigen Stellen, welche beliufs unikroskopischer Untersuchung excidirt wurden, zeigten keine Recidivo mehr. Die Excision werde demnach, bei der Resultatlosigkeit aller inneren und äusseren Mittel, das beste Mittel sein in F'ällen, wo das Xautholasma nur in einzelnen Exemplaren auftritt.

Horovitz.

Chambard. Das vorübergehende Xanthom der Diabetiker und seine nosologische Bedentung. (Annal. de Dermatologie et Syph. 1884.)

An der Hand von sechs aus der Literatur geschöpften Fällen von Xantlielasma bei Diabetikern crörtert Ch. seine Anschauungen über den Zusammenhang zwischen Diabetes mellitus und Xanthom. Der causale Zusammenhang zwischen diesen zwei Erscheinungen wird aus dem parallel neben einander verlaufenden Schwanken derselben ersehlossen, so zwar, dass bei Besserung der Zuckerharmruhr die Knütcheneruptionen abnehmen, bei Zunahme der ersteren jedoch zunehmen. Die Entstehung der Knütchen selbst erklärt Ch. aus der Reizung der Hautgebilde durch den im Blute circulirenden Zucker. - (Xanthomeruption auf der allgemeinen Hautdecke wäre demnach diagnostisch für Diabetes mellitus za verwerthen und der Fingerzeig, den Harn auf Zucker zu untersuchen.)

Horovit\%.

Cacciola. Fall von Morbus Addisonii. (Gazz. med. ital. 15. 1884.

- Giorn. ital. dollo mal. ven. e della pelle. 3. 1884.)

Der Autor bespricht die Ansichten, welche über die Broncekrankheit herrschen und theilt folgenden Fall mit: Ein 35jähriger Mann bemerkte $1 \frac{1}{2}$ Jahre vor seinem Tode, dass seine Haut sich inmer mehr bräune, womit Schwäche, Schwindel, Apathie, Fieber und Frost verbunden war, die zu letalem Ausgang führten. Die Section und mikroskopische Untersuchung ergaben: vollständige Zerstörung beider Nebennieren, welche von verkästen und verkalkten chronisclientzürdlichen Produkten ersetzt sind, Schwellung der lymplatisehen und gruppirten Follikel des Darmes. Schwarzes nud gelbes Pigment in 
verschiedenen Organen, besonders an der Haut und Mundschleimhaut deponirt, gleichzeitig damit kleinzellige Infiltration der oberffächlicheil Schichten des Derma. Die Ganglien und sympathischen Fasern selbst mitten in den Nebcnnieren unverändert.

Finger.

Sangalli. Ueber den Zusammenhang yon Veränderungen der Nebennierenmit der Broncekrankhoit der Haut. (Arch. clin. ital. di Roma 1884. Giovn. ital. delle mal. vell. e della polle 3, 1884.)

Ohne in theoretische Auseinandersetzungen einzugehen, berichtet S. über vier Fälle eigener Beobachtung: 1. Patient starb an Gastroenteritis. Section: Nebennieren doppelt so gross als normal, die rechte mit der unteren Leberfäche, die linke mit der Vorderfläche der entsprechenden Niere verwachsen. Das Parenchym in eine gelbliche, derbe Masso umgewandelt, die von blassgelben. Streifen durchzogen ist. Die mikroskopische Untersuchung ergibt fibrilläres Gewebe mit reichlichen Granulationszellen und Fett, kein normales Pigment. Die Haut schmutzig gelbbraun. 2. Wuib an Tabes gestorben. Die Haut erdiggelb. Die linke Nicre in einen klein-knotigen Tumor von $21 \mathrm{Ctm}$. Länge, $13 \mathrm{Ctm}$. Breite (Sarcom), umgewandelt, die entsprechende Nebenniere faustgross, von gleicher Beschaffenheit wie die Niere. 3. Ein Knabe blieb, nachdem er mit eine: schweren Last am Rücken eine Treppe heruntergekollert war, wio todt liegen, erholte sich, aber seine Hant erhiclt Broncefarbe, welche Färbung: Penis und Scrotum übrigens schon in seiner Jugend darboten. Puls langsam, Respiration verlangsamt, A pathie, grosse $S c h w a ̈ c h e$, letaler Ausgang. Section: Nieren blutreich, Nebennieren doppelt so gross als normal, von tief rother Farbe, von hirsekorngrossen, gelblichen, unregelmässigen Flecken durchsetzt, die erweichten Tuberkelı ähnlich sind. 4. 32jähriger Mann, starb an ausgesprochener Addison'scher Erkrankung. Section: Haut des Gesichtes, des Halses, der Vorderarme, Handrücken broncefarbig, Lippen und Zahnffeisch bleifarbig. Alte pleuritische Adhäsionen, linke Nebenniere in käsige Substanz umgewandelt.

Finger.

Guaita. Eine eigenthümliche Erkrankang der Haut bei Kindern nach dem Gebrauch des Arsen. (Arch. di Patologia in. fantile III. 1884. - Giorn. ital. delle mal. ven. e della pelle 5, 1884.)

Seit Jahren verwendet der Autor bei der Arsenbelandlung kleiner Kinder die Sol. Fuwleri, die er, mit zwei Tropfen begimnend, alle 4, 
6, 10, 15 Tage mit 2 Tropfen steigend, bis 18-20 Tropfen nehmen lässt. In manchen Fällen dieser Behandlnng bemerkte er eine eigenthümliche Verfärbung der Haut, welche sich allmählich entwirkelt, Hand in Hand mit dem Gebrauch des Arsen geht und mit dem Ab. schluss der Kur endet, odor aber in anderen Fällen erst auftritt, nachdem der Arsengebrauch ausgesetzt wurde. Diese Verfärbung der Haut ist der Broncekrankheit ähnlich, hat die Färbung des Grafit, wie wenn man die Finger mit Bleistiftstanb verunreinigt. Sie tritt um Hals, Brust, Bauch und an den Händen auf. Weniger deutlich ist sie im Gesicht, den Schenkeln, dem Rücken. Sie ist nie von Störungen des Allgemeinbefindens begleitet, verschwindet nach circa einem Monat und hinterlässt Abschuppung der Haut. In einem einzigen Falle trat die Verfürbung anch auf beiden Handtellern und Fusssohlen auf, heilte mit so starker Desquamation, dass der Gebrauch der Schuhe und das Gehen durch einige Zeit behindert war. Die erkrankten Kinder hatten das Alter von zwei bis zehn Jahren, bei Kindern unter zwei Jahren und bei Säuglingen bemerkte er dic Eikrankung nie.

Finger.

Hume. Das Ulcus rodens und sein Zusammenhang mit Epitheliom. (Brit. med. Journal. 5. Juni 1884.)

Vf. hatte Gelegenheit acht Fälle von Uleus rodens klinisch und mikroskopisch zu untersuchen. Die erste Veränderung, welche das Mikroskop sehen lässt, ist Vergrösserung der Haarfollikel, Vermehrung ihrer Zellen, Ausbuchtung der Follikel. Zuir selben Zeit kommt es za Irritationserscheinungen im Corium, Oedem, Answanderung von Blutkörperchen, kleinzelligen Infiltraten. Dadurch erscheinèn Talgdrüsen und Haarfollikel wie tiefer in die Haut eingedrungen. Weiters komme es zu Zerklüftung der Follikel, and dadurch zum Beginn des Ulcus rodens. Diese Umwandlung wird begleitet von Wucherung der Zellen des Rete, die oft Stäbchenform annehmen, während die Haarwurzel besenförmig aufgelöst wird. Gleichzeitig treten auch Veränderungen in den Talgdrüsen auf. Die Membrana propria wird der Sitz einer kleinzelligen Proliferation, die Talgdrüsenzellen gehen retrograde Metamorphosen ein, werden granulirt und verlieren ihre Kerne. Globes epidermiques hat Verf. nicht finden können, doch können sie durch halbzerstörte Talgdrüsen vorgetäuscht werden, oder aus den Ueberresten der Haarfollikel resultiren. Die Epidermis ist atrophisch 
und in der Umgebung des Geschwürs ausser Zusammenhang mit den Talgdrüsen. Verdickung der Epidermis war nur gleichzeitig mit entzündlicher Infiltration, also als secundäre Veränderung nachzuweisen. Die Schweissdrüsen zeigen keine activen und nur sehr spät secundäre Veränderangen, retrograde Zellmetamorphosen. Durch dies sei Thin's Ansicht, das Ulcus rodens sei ein Adenom der Schweissdrüsen, widerlegt und der Schluss gerechtfertigt, es sei-dasselbe eine specielle Form von auf Talgdrüsen und Haarfollikel beschrïnkten Epithelioms, welches in Folge des Einschlusses in fibröse Membranen nur beschränktes Wachsthum und keine Infection der Lymphbahn zeige.

Finger.

Blum und Duval. Du cancroide de la peau. (Arch. gén. de Méd. p. 130-145. 1883. - Ctlbl. f. kl. Med. Nr. 18, 1884.)

Nach den Verff. weicht, ganz abgesehen von den Differenzen zwischen Schleimlant. und Hautkrebs, der klinische Charakter der in unmittelbarer Nachbarschaft der Orificion entstehenden Formen von jenen, welche ihren Ursprung auf der Oberfläche der Haut fern von jeder natürlichen Oeffnung nehmen, bedcutend ab.

Bekannt ist die Sonderstellung, welche das Ulcus rodens im Bereich der oberen zwei Drittheile des Gesichtes bezüglich scinrs Verlaufs und seiner Prognose bei aller sonstigen Analogie mit dem Cancroid einnimmt. Verff. zeigen an der Hand der letzten Arbeiten über diesen Gegenstand (insbesondere von Devergie, Thiersch, Warrens, Thin und Sangster), dass eine anatomische Differenzirung beider Formen nicht besteht, ja dass vom anatomischen Standpunkte aus sogar das Epitheliom mit gewissen, unter dem Namen Extremitätenlupus beschriebenen Affectionen identisch sei. In gleicher Weise, wie die oberen Partien des Gesichts exclusiver Sitz einer ganz bestimmten Form des Cancroids sind, zeichnen sich die - übrigens sehr seltenen - Epitheliome der Hand durch ganz besondere Eigenschaften aus. Dieselben werden nämlich nur zwischen dem 60 . und 80. Lebensjahre angetroffen, und die weitaus grösste Mehrzahl entwickelt sich aus alten Narben (von Verbrennungen selbst ans der ersten Kindheit, Schussverletzungen etc.). In einer eigenen Beobachtung der Verff. folgte die Entwicklung eines Handrückenkrebses unmittelbar auf ein Trauma (Abschürfung durch einen Getreidesack). Weiter wird aus einem zweiten, auf das genaueste, namentlich in 
histologischer Hinsicht erschlossenen Fall von Handkrebs gefolgert, dass das Hautepitheliom seinen Ursprang in den interpapillären Bezirken des Rete Malpighii nimmt, während die Haarfollikel, Talgnnd Schweissdrüsen sich an der Neubildung nicht betheiligen, allenfalls Difformitäten durch Compression erleiden, des Ferneren, dass der Rückgang des Tumors durch einen entzündlichen Process der Hant bedingt ist, derart, dass dic Entwicklung eines Narbengewe. bes erfolgt, welches die Läppchen der Neubildung einschnürt und zur Resorption bringt.

Pulvermacher. Eine Familienepidemie von Pemphigus idiopathicus. (Monatsh. f. prakt. Dermat. Nr. 2, 1885.)

P. theilt die seltene Beobachtung von gleichzeitigem Auftreten eines Pemphigusexanthoms (? R.) bei einem neugeborenen Kinde, dessen 4jahriger Schwester and der Mutter beider Kinder mit. In dem Inhalte der Pemphigusblasen der beiden Kinder fanden sich enorme Mikrococcenmengen, welche in ihrer Form und Gestalt den Neisser'schen Gonococcen vollkommen glichen, ohne dass aber eine gonorrhoische Affection von Seite der Eltern nachweisbar war. Der Vater der Kinder litt einige Wochen vorher an einer herpetiformen, nicht näher charakterisirten Hautaffection, welche er angeblich durch Ansteckung von einem Pferde acquirirt hatte. - Lues war bei allen Pati'nten mit Sicherheit auszuschliessen.

Hochsinger.

\section{Chorioblastosen (Wachsthums-Anomalien der Haut von bindegewebi- gem Ursprung and Typus A.).}

Doutrelepont. Fall von Meningitis tuberculosa nach Lupus; Tuberkelbacillen im Blute. (Deutsche medicinische Wochenschrift Nr. 7. 1885.)

D. beobachtete, dass Tabereulose der Knochen, Gelenke und der inneren Organe bei bestehendem Lupus sich hănfiger entwickle, als man früher dachte, ja, dass sogar Miliartuberculose besonders nach blutigen Eingriffen an lupōs erkrankter Hant entstehen kann. Es warde ferner gezeigt, dass Eiter, welcher von tieferen tuberculösen Herden stammt, auf der Haut wahren Lupus za ercengen rermöge. Fl aslund gegenüber betont D., dass unter den 26 Lupuskranken in 
deren Lupus er Tuberkelbacillen fand, keiner nachweislich an Tuberculose anderer Organe litt, auch war hereditäre Belastung ausge. schlossen. Bei einem 18 Jahre alten Mädchen mit Lupus im Gesichte und normalen Lungenspitzen kam es za tuberculöser Meningitis und Exitus letalis. Etwa eine Woche vor dem Tode wurde ans der gesunden Haut der Backen Blut entnommen und D. konnte unter 10 nach Ehrlich's Vorschrift behandelten Deckglaspräparaten 3 Tuberkelbacillen constatiren. Blutproben aus der Vena jugularis interna und dem Herzen enthielten einige Tuberkelbacillen. Die Section erwies, dass die tuberculosen Erscheinungen an der Basis cranii, ferner diejenigen der Lungen und des Darmes frischen Datums waren und also eine Invasion von Tuberkelbacillen von der kranken Haut in die inneren Organ $\theta$ stattfand.

Hor ovitz.

Schwimmer. Zur Therapie der schweren Lupusformen. (Wiener med. Wochenschr. 20-22, 1884.)

Selbst die eingreifendsten und radicalsten chirurgischen Behandlungsmethoden des Lupus, wie die Auskratzung, Ausschneidung oder Ausbrennung mit dem. Thermo- oder Galvanocauter.(Besnier), lassen bei ausgebreiteten und schweren Lupusformen in vielen Fällen im Stiche, und vermögen nicht immer dauernde Heilung oder Besserung herbeizuführen und Recidiven zu verhäten.

Verfasser ist daher in letzterer Zeit zu einem minder eingreifenden, ziemlich schmorzlosen und einfachen Verfahren übergegangen, welches or während einer $1 \frac{1}{2}$ jährigen Beobachtungsdauer an 20 schweren Lupusfällen erprobt hat und wegen der mit demselben erzielten, überaus günstigen Erfolge auf das wärmste empfiehlt.

Die lupös erkrankten Hautpartien werden lämlich nach vorhergegangener Entférnung der auflagernden Borken und Krusten mittelst Vaselineinfettung mit einer 10percentigen Pyrogallussäuresalbe, welche dreimal des Tages zu wechseln ist, durch 4-7 Tage verbunden, hierauf im Stadium der profusen Eiterung mit grauem Quecksilberpflaster durch 10-14 Tage bedeckt gehalten und dann dem weiteren Ver. narbungsprocesse überlassen.

Die Combination dieser Mercurialbehandlung mit der Anwendung der Pyrogallussäure bezweckt die Hintanhaltung von emeuerter Knötchenbildung, also die Lupusrecidive in der jungen Narbe. Die Erfahrung habe nämlich gelehrt, dass bei einfacher Aetzung mit Pyro- 
gallussäure das lupöse Gewebe zwar rasch zerstört wird, dass aber nichtsdestoweniger in der daraus resultirenden Narbe fast immer frische Knötchen und Infiltratbildung zum Vorschein komme.

Ein ähnliches therapeutisches Verfahren hat vor Karzem Doutrelepont angegeben, welches in der Application 0.10\% iger Sublimatcompressen auf den lupösen Boden nach vorherigem Evidement des erkrankten Gewebes besteht. Während jedoch Doutrelepont, von der bacillären Natur der Lupnserkrankung durchdrungen, die günstigen Erfolge dieser combinirten localen Mercurialbehandlung auf die pilztödteıden Eigenschaften des Sublimats zurückführt, erklärt S. dieselben lediglich als das Resultat der resorbirenden und „dynamisch-chemischen Wirkung" des Mercur, wobei er betont, dass für ilın die Identität des Lupus mit Hanttuberculose noch nicht genügend erwiesen sei.

Die Vorzüge der Schwimmer'schen Methode sind nach dessen Angabe: Geringe Sclımerzhaftigkeit, relativ kurze, höchstens auf $3-4$ Monate sich erstreckende Behandlungsdauer, bei allen Fällen mögliche Durchführbarkeit, besonders günstige Wirkung bei schweren ulcerösen und serpiginösen Formen sowie die Heilung mit schöner, glatter Narbenbildung.

Hochsinger.

Lesser. Zur Behandlung des Lupus mit Arsenik. (Centralbl. für die medis. Wissenschaften. 1885.)

Anknüpfend an Buchner's Versuche von Behandlang der Lungentuberculose mit Arsenik unternahm L. die Behandiung des Lnpus wit diesem Mittel, ohne die Krankheit, wie es Doutrelepont thut, durch Localtherapie zu beeinflussen. Folgt ein kurzer Bericht über 5 Fälle. In einem Fall war kein Etrolg zu verzeichnen, in den 4 übrigen Fällen sei der günstige Erfolg, indem die Infiltrate schwanden, klar zu Tage getreten. L. plaidirt für grosse Dosen durch lange Zeit, 0.02 bis 0.03 pro die innerlich oder Sol. Fowlerie 0.17 bis 2.0 pro injectione.

Horovitz.

Marshall. Behandlung des Lupus vulgaris mit Salicylsäure. (Brit. med. Journal Nr. 1226, S. 1253, 28. Juni 1884.)

Marshall hat Salicylsäure in der Form einer Salbe als Mittel gegen Eczem, besonders des behaarten Kopfes, sowie gegen Impetigo contagiosa, besonders kleiner Kinder mit dem besten Erfolge Vierteljahresschrift f. Dermatol, 1. Syph. 1885. 
angewendet. Dadurch wurde er voranlasst, das Mittel auch bei anderen Hautkrankheiten zu verwenden.

So behandelte er einen schweren Fall von Lupus exedens bei einem 25jährigen $W$ eib, der den Nasenflügel, die Wange und das Augenlid derselben Seite fast ganz zerstört hatte. Er verwendete zuerst Salben von 1:35 Vaselin und stieg rasch bis anf $5: 35$. Die Geschwüre begannen rasch zu heilen, es erschienen keine neuen Knoten mehr (? R.), die Narben waren weich und glatt. Innerlich nahm Patientin gleichzeitig die Solutio Donovani mit Eisen, nachdem dieselbe aber schon früher längere Zeit erfolglos geworden war, schrieb der Autor clerselben bei dem gegenwärtigen Effecte krinen weiteren Antheil zu.

Finger.

Besnier. Der Lupus und seine Bohandlnng. (Annales de Dermatologie et de Syphiligraphie T. VI. 1885.)

R. betont zunächst das streng abgegrenzte klinische Bild des Lupus and weist die Einwendungen zurück, dass die Diagnose Lupus in zu ausgedehntem Masse gestellt werde. Fülle, in welchen man die Diagnose nicht sofort stollen kann, seien selteno Ausnahmen.

Zweifelhaft kann die Diagnose sein bei gowissen abgelanfenen Formen von Lupus erythematosus des Gesichtes oder der Extremitäten, der Hände, der Augenlider, des beharten Kopfes, gegenüber erosiven oder atrophischen Formen der. Acne. Auch atypischer Verlauf des Lupus mit Entstehung von Hyperkeratosen, Papillomen und Verstümmẹlungren kann die Diagnose erschweren.

Anlass zu einer Verwechslung mit Lupus können geben gewisse Formen der Syphilis, der Lopra und der Sclerodermia mutilans.

Die Dermatologen, welche die nosologische Einheit des Lupus und der Tuberculose in Abrede stellen, stützen sich hauptsächlich auf drei Punkte:

1. Auf das verschiedene Aussehen von Lupus und Hauttuberculese.

2. Auf den strittigen Charakter der Beziehungen zwischen Lupus und Tuberculose der anderen Organe, speciell der Lunge.

3. Messen sie den Beweisen, welche die Histologie und die Experimentalpathologie liefert, nur einen zweifelhaften Werth bei.

Die Verschiedenheit des Aussehens fällt allerdings sehr in die Augen, aber sie findet sich ja anch bei carcinomatösen und syphilitischen Hautaffectionen. 
Gleichwie die Hauterscheinangen der hereditären Syphilis von denen der tertiären verschioden sind, so hat anch die primäre Fuberculose der Haut (Lupus) nicht die Charaktere der infectiösen oder tertiären Tuberculose, welche allein auf der Haut oder auf den Schleimhäuten in Form von typischen sogenannten tuberculösen Granulationen and Ulcerationen auftritt.

Von diesen beiden Läsionen ist die eine eine locale äussere Tuberculose, welche sich in langer Zeit local an einem nicht inficirten Individuum entwickelt; die andere ist eine Erscheinung der vollzogenen Allgemeininfection, welche immer dem Auftreten auf der Hant vorausgeht.

Was das Verhältniss von Lupus zur Tuberculose der anderen Organe betrifft, so verweist Besnier auf seine früheren Publicationen und auf eine These von Renouard (Paris 1884). Er wiederholt, dass seine Lupuskranken in der Mehrzahl der Fälle einen scrophulüsen Habitus im Sinne der alten Autoren zeigten, welcher für die Aufnahme und Entwicklung der tuberculösen Keime einen günstigen Nährboden bilde. Die Phthise entwickle sich bei den Lupösen gewöhnlich latent und sehr langsam. Dies hat die Beobachter von dem wahren Sachverhalt abgelenkt und die hentige Meinungsverschiedenheit hervorgerufen.

Schon ehe die Histologie und das Experiment die Beweise für die Idenditität des Lupus und der Tuberculose gebracht hatten, war Besnier durch seine klinischen Beobaclitungen zu dom gleichen Resultat gekommen.

Keine Behandlungsmethode passe für alle Fälle. Alle Methoden, welche mechanisch oder chemisch die Lupusknötchen zerstören, welche eine exsudative Entzündung, welche zur Abstossung der Lupuselemente führt, hervorrufen, seien zu verwenden.

Die von Besnier eingeführte Cauterisationsmethode mit Hilfe des Thermocanter passe für die Mehrzahl der Fälle. Für din Lupus der Conjunctiva, der Nasenhöhlen, der Mund- und Rachenschleimhaut sei sie die einzig anwendbare; bei allen Fällen, wo man von Zeit zu Zeit nachhelfen muss, die leichteste und sicherste.

Nur bei alten, sehr ausgedehnten Lupusfallen, welche schon zu Verstümmelungen geführt haben, sei die Cauterisationsmethode nicht zu verwenden. Solche Fälle behandle man am besten mit Pyro- 
gallussãure, in Salbenform oder in ätherischer Lüsung. Die lupösen Flïclen werden entweder mit einer gesättigten ätherischen Lösung der Pyrogallussäure bepinselt oder dieselbe wird mit dem Spray applicirt. Die Haut über\%ieht sich sofort mit ciner weissen und adhäsirenden Schicht von Pyrogallussäure, welche mit einer Schicht 'l' aumaticin bedeckt wird.

Bis die Eiternng das Traumaticin durchbrochen hat, kann man sich den Verband ersparen. Eine einzige Anwendung genügt, um die frwünschte Dernatitis zu erzeugen.

Für den Lupus erythematosus ist die Elektrocanterisations. methode dic empfehlenswertheste Art der Behandlung. v. Zeissl.

Minich. Ueber Lepra im Süden Russlands. (Wratsch Nr. 39 bis 41, 1883. -- Centralbl. f. Chir. Nr. 2, 1884.)

Nach M.'s an Ort und Stelle angestellten Beobachtangen kommt die Lepra über den ganzen Süden Russlands zerstrent vor: in Bissarabieu, den Gouvernements Cherson, Jekaterineslaw, Saurien, im Lande der Donschen Kosaken, im Kubanschen und Terschen Gebiet und im Gouvernement Astrachan. M. hat im Ganzen etwa 120 derartige Kranke genauer untersucht, die meisten derselben im Astrachanschen Gouvernement. Die Krankheit in Süden Russlands unterschtidet sich in nichts ron der Lepra, wie man sio in Norwegen, Palästina, Japan, Madeira etc. beschrieben hat. Sie tritt eben so als tuberöse, anïsthetische und gemischte Form auf. Rfine Fälle der anästhetischẹ Lepra kommen übrigens höchst selten vor, ausser in der Ortschaft Karatschai im Kubanschen Gebiet. Nicht oft trifft man auch die reine tuberculöse Form; die bänfigste ist die gemischte.

Hinsichtlich der Aetiologie der Krankheit weist M. die Buschuldigung der atmosphärischen und tellurischen Verhältnisse so wie der Lebensweise zurück. Grössere Contraste in dieser Beziehung, als die von $M$. bei den verschiedenen Kranken angetroffenen lassen sich kaum denken, so z. B., wenn man das Astrachansche Gouvernement mit dem Kubansehen Gebiet vergleicht. Ersteres wird von dem unter dem Meeresspirgel lingenden Boden des ehemaligen kaspisch-aralschen Meeres gebildet, ist eine kahle Steppe mit einer spärlichen Vegetation and ohne jegliche Waldungen; die Brumnen enthalten nicht selten bitter-salziges Wasser, die Speise der Einwohner besteht meist in Fischen, die Wohnungen sind relativ geräumig and reinlich, die Be- 
schäftigung ist meist Fischfang, weniger Ackerban oder Vichancht. Dagegen liegt die Ortschaft Karatschai im Kubanschen Gebiet am westlichen Abhang des Elbrus etwa 5000 Fuss über dem Meeresspiegel, wird von vor Jahrhunderten eingewanderten krimschen Tataren bewohnt, liegt in einer üppigen und malerischen Berggegend mit reichen Laub- und Nadelwaldungen; die Flüsse beziehen ihr Wasser von den Eisfeldern des Elbrus; dio Bewohner, Nomaden, bekannt durch die Gäte ihres Virhes, zithen den Sommer über ins hohe Gebirge, nähren sich hauptsächlich von Milch und deren Produkten (hier ist die Heimat des Kefir), ferner von Fleisch; von Reinlichkeit existiren bei den Einwohnern in Kleidung und Lebens. weise auch nicht die elementarsten Begriffe, die Wohnung wird nicht selten von einer Gebirgsgrotte oder Felsenspalte gebildet. 'Irotz dinser Verschiedenheit ist in einigen Ortschaften des Astrachanschen Gouvernements unter der rassischen Bevölkerang die Lepra so verbreitet, dass bis $1 \%$ der Bewohner krank sind; in benachbarten tatarischen Dörfern kommt dagegen die Lepra nicht vor and unter den Kalmüken höchst selten. Descrleichen liegen in dor Nachbarschaft des lepra. reichen Karatschai je ein osetimsches und ein kabardinsches Dorf mit 40 jüdischen Familien, bei doren lieiner sich Lrpröse finden.

Auch die Nälie des Mecres als ätiologisches Moment wird von M. anf Grundlage der von ilm gesammelten Daten zurückgewiesen.

Dagegen wird als einziger Weg der Verureitung die Uebertragung angesthen durch hercditäre oder directo Infection. Zunächst wird auf die anfaullige Thatsache hingewiesen, dass die Krankheit, trotz der Verschiedenheit der Sprachen, an der-Wojga wie am Don, am Terek wie am Kuban "Krymka" genannt wird. Gegen die Heredität sprechen mehrere Umstände. So werden die Hauptherde der Krankheit im Astrachanschen Gouvernement von Dörforn gebildet, dic erst in den letzten Jahrzehnten durch Einwanderung aus Gegenden entstanden, wo die Lepra nicht vorkommt. In diesen Dörfern beobachten dif Einwohner keine Isolirung der Kranken von den Gesunden. Bei den älteren Einwohnern des Astrachanschen Gouvernements dagegen ist dio Lepra. längst bekannt und gilt allgemein für so ansteckend, dass einerseits Leproserien erbaut wurden, anderseits irn Fall der Erkrankung für das betroffene Glied der Familie eine isolirte Lehmhütte erbaut wird, in der dasselbe den Tod erwartet. In solchen Dörfern ist die Lepra bereits erloschen, sind die Leproserien zum 
Theil geschlossen, oder die Krankheit ist in Ellöschen begriffen: Umgekehrt dagegen gibt es keine solche Isolirung der Kranken in Gegenden der. Wolga, des Don, Kuban etc., und daher denn hier auch eine grössere Verbreitung der Krankheit. Verf. führt ferner in teressante Beispiele an, die anfänglich für die Heredität zu sprechen scheinen, sich aber bei gonauerem Zusehen als durch directe Uebertragung entstanden erklären - wenn man nur seine Daten an Ort und Stelle and nicht in Krankenhause sammelt. Desgleichen werden Beispiele aufgeführt, dje für directe Infection sprechen. Zum Zustandekommen der letzteren wirken übrigens verschiedene Unstände mit: Disposition, vielleicht gewisse Stadien der Krankheit etc.

Die Volksmedicin weridet gegen die Krankheit antisyphilitische Nittel, Quecksilber und Decocte an. Die Allgemeinernährung leidet darunter, die Röthe des Gesichtes schwindet und die Knoten werden kleiner; doch dafür tritt um so rascher der allgemeine Marasmus ein.

Profeta. Ueber Elephantiasis Graecorum. (Giorn. internat, delle Scienze mediche VI. - Giorn. ital. delle mal. ven. e della prolle 5. 1884.)

Verfasser berichtet über 9 Fälle von $L$ epra, in denen er zunächst auf Bacillen untersuchte. Die Untersuchung wurde in der Woise vorgenommen, dass durch Einstich mit der Lancette oder der Staarnadel Blut gewonnen, in Capillarröhrchen mit einer kngeligen Auftreibung in der Mitte aufgesaugt und dann die Capillarröhrchen in der Flamme geschlossen wurden. Zur Färbnng benützte $\mathbf{P}$. cino $5 \%$ alloholische Lösung von Anilinviolett, rein oder mit Wasser verdünnt. Die Untersuchung warde entweder gleich angestellt oder das Blut in den Capillarrōhrchon bis zu 40 Tagen gelassen. Die Untersuchungen des Blutes, das theils gesunden, thrils an Lepra tubcrculosa erkranliten Hautstellen Lepröser entnommen wurde, fielen in Bezug auf die Gegenwart von Bacillen in 3 Fällen positiv, in 4 Fällen negativ ans. Der Autor ist nicht der Ansicht, dass die im Blute gefundenen Bacillen Ursache der Erkrankung sind, nachdem er sie nicht constant gefunden hat. Ueber das Contagium der Lepra hat er schon 1868 eine Reihe von Experimenten mit negativem Erfolge angestellt, denen er jetzt 10 neve hinzufügt, indem er 10 gesunden, kräftigen Individuen Blut in Scarificationswunden einrieb, das er thoils gesunden Hautstellen, theils den Knoten Lepröser entnommen liattc. 
Alle 10 Versuche waren nach $120-334$ Tagen noch resultatlos geblieben. (Negative Erfolge von Experimenten beweisen positivon Erfolgen Anderer gegenüber nicht das Mindeste. R.)

Finger.

Baumgarten. Ueber die Unterscheidungsmerkmale der Bacillen der Tuberculose und der Lepra. (Monatschr. f. prakt. Dermatol. Nr. 7. 1884.)

Im Gegensatze zu Neissor und Babes kann B. weder in den Form- noch Grōssenvorhältnissen etwas Charakteristisches für die Differenzial-Diagnose beider Bacillenarten finden. Auch der Sitz der Bacillen, ob intracellulär bei Lepra oder extracellulär bei Tuberculose, lasse sich nicht für beido Bacillenarton in allen Fällen strenge aufrecht erhalten. Es existiren auch keipe principiellen Färbungs-Differenzen zwischen beiden Bacillenarten, sondern nur recht erhebliche graduelle Unterschiede der Entfärbbarkeit, dcren richtige Verwerthung aine Differenzial-Diagnose zu stellen ermöglicht. Die WachsthumsErscheinungen der Leprabacillen anf künstlichen Cultursubstraten kennt B. aus eigener Anschaung nicht, doch die Angaben Hansen's, nach welchen die Leprabacillen in den küustlichen Nährboden (erstarrtes Blutsorum) eindringen, denselben verflüssigen und nach acht 'Tagen eine reichliche, sich leblaft bewegende Brut erzeugen, was Tuberkelbacillen nie bewirken, könne differenzial-diagnostisch verwerthet werden. Endlich sei das Verhalten beider Bacillenarten zum lebenden Thierkörper wichtig, indom die Tuberkelbacillen, geimpft in die vordere Augenkammer des Kaninchens, eine allgemeine Infection hervorrufen; bei den Leprabacillen jedoch finde dies nicht statt.

Horovitz.

Guttmann. Ueber Leprabacillen. (Berliter klin. Wochenschrift Nr. 6. 1885.)

Guttmann weist nach eigenen Untersuchungen auf die Eigenbewegung der Lrprabacillen von frisch excidirten Stücken hin. Nimmt man aus solchen mit einer Staarnadel ein kleines Partikelchen heraus, zerreibt es anf dem Objecttrăger zu dünner Schichte in einem Tropfen destillirten Wassers und untersucht nun bei Oelimmersion und Abbe'scher Beleuchtung, so sieht man - was A. Hansen zu der Entdeckung der Bacillen führte - zahlreiche Stäbchen in leb- 
hafter, hin- und herschmellender Bewegung, die an die der Fäulnissbacillen im Harne rinnert. Dis meisten Bacillen fand G. sporenhaltig. Bei vielen sieht man beido Enden mit jo einer Spore besetzt, so dass sie hantclförmig aussehen; bei der Mehrzahl aber sind 3, 4 Sporen in nicht durclians gleichen Abständen von einander an dem Längsdurchmesser des Bacillus angereiht, so dass er perlschnurfürmig aussieht. G. bestätigt die Angaben Baumgarten's, dass die Leprabacillen sich rascher fürben lassen als die Tuberkelbacillen. Während letztere in Schnittpräparaten erst nach stundenlanger Färbung in voller Deutlichkeit erscheinen, könne man Leprabacillen in Schnittpräparaten schon nach nur drei Minuten danernder AlkoholFuchsiu-Anilin-Wasserfärbung und Muthylenblau-Nachfärbung diese Methode hält $G$. für die beste - als rothe Stäbchen auf blauem Grunde sehen. Uebrigens hätten die stets bacillenfreie OberJaut, Haare, Nägel in geringerem Grade dieselbe Eigenschaft, wie die Leprabacillen, den áufgenommenen Anilinfarbstoff fixirt zu erhalten gegenüber der Einwirkung einer entfärbenden Substanz oder der Imprägnation des Objecte's mit einer zweiten Farbe; sie erschienen also bei obigrem Verfahren anch roth. Gegenüber der grossen Achnlichksit von Lepra. und Tuberkelbacillen in den gefärbten Trockenpräparaten auf Deckgläsern hebt $G$. hervor, dass die häufige Lagerung der ersteren in Zellon sie von den Tuberkelbacillen untrr. scheide, die bei solchen Trockenpräparaten aus phthisischem Sputum und zerfallendem Inhalte von Cavernen stets frei liegen neben Zellentrümmern. In Schnittpräparaten aus phthisischen Geweben und Organen liegen dagegen die Stäbchen vielfach in Zellen, besonders auch Riescuzcllen.

Caspary.

Köbner. Ueber Lepra. (Berliner klin. Wochenschr. Nr. 2. 1885.)

Bei der Discussion gelegentlich der Vorstellung eines Leprakranken in der Berliner medic. Gesellschaft demonstrirte Köbuer ihm ans Würzburg zugeschickte Flüssigkeit von Pemphigus leprosus, einem bisher für zweifellos trophoneurotisch gehaltenen Krankheitszeichen. In jeder der Blasen aber, die in dem Würzburger Julius-Hospital unter den Augen der Beobachter auftrat, hat der Assistent der Gorhardt'sclıen Klinik, Friedrich Müller, massenhaft Bacillen nachgewiesen, die grösstentheils in weissen Blutkörperchen oder in bereits vergrösserten vorhandon, sich sehr selten frei in der Flüssigkeit 
befanden. Ferner weist $K$. auf eine biologische Differenzirung des Lepra- und Tuberkelbacillus hin, die ihm erheblicher erscheint, als alle tinctoriellen oder sonstigen subtilen Differenzen in Gestalt, Lage oder Anordnung innerhalb oder ausserhalb von Zellen: den Unterschied in der Infectiosität implantirter Massen. Während in die vordere Angenkammer iuplantirte Tuberkelmassen ohne Ausnahme und selbst in minimalsten Mengen rasch infectiös auf die Nachbargewebe im Auge und in wenigen Wochen auf den ganzen Organismus wirken, ist bekanntlich bei Köbner's vielfachen Uebertragungen grösserer Lepraknötchen jeder derartige Effect ausgeblieben (siehe Referat in dieser Vierteljahrschr. 1882, S. 576). Zwei neuere Untersucher sind nun glücklicher gewesen, insoferne sie wenigstens eine locale Lepraaffection nachgewiesen haben. Der eine war Damsch (siehe Ruferat in dieser Viertejjaluresschrift 1883 , s. 636), der eben geringe locale Nachbarinfection im subcutanen Fettgewebe einer Katze beobachtete, der er eine Implantation in der Peritonealhöhle gemacht hatte; der Ersatz in der vorderen Angenkammer war noch geringer. Weiter gekommen ist Vossius in Königsberg, der unter der Leitung von Baumgarten gearbeitet hat. Derselbe lat auf der letzten Heidelberger Ophthalmologen-Versammlung berichtet, dass er Neoplasie von Leprazellen. sowohl in der Cornea als in der Iris und in Corpus ciliare erzielt habe. Vossius bezieht das Gelingen seiner Versuche gegenüber denen von $\mathrm{Köbner}$ auf die von ihm erzeugte, die Invasion von Bacillen in den entzündlich aufgelockerten Augenhäuten begünstigende circumscripte Kerato-Iritis mit Synechien. (Etwas alterirend klingt die von Köbner erwähnte Angabe Vossius, dass sein Impfmaterial einem Brüderpaare aus Memel entrommen war, das angeblich nie in Aussatzgegenden gelebt habe, noch auch mit Aussatzkranken in Berührung gekommen sei. Referent, der den Kranken gesehen und Memeler Aerzte übır die Anamnese befragt hat, erhielt die Bestätigung der obigen Angaben und zugleich die Nachricht, dass am kurischen Haff mehrfach autochthone Leprafällo beobachtet seien. Referent hat eindringlichst auf die Beobachtung und Isolirung der Kranken hingewiesen.) - Endlich referirt $\mathrm{K} \ddot{b} \mathrm{bn}$ er über die Bestätigung seiner positiven Bacillenbefunde in den Blutproben aus gesund erscheinender und späterhin gesund bleibender Haut Lepröser, bei denen unter schweren acuten Symptomen offenbar Transporte von Bacillen in alle Körpergewebe staltgefunden hatten. Nach solchen Eruptionen - und 
inmer crst nach solchen - fanden Majocchi und Pellizari, Thin, F. Müller-Würzburg, de Amicis, wie frülıer Köbner Bacillon in dem circulirenden Blute an früher nit negativem Resultate untersucliten Hautstellen.

Caspary.

Virchow. Ueber lepröse Milz. (Berl. klin. Wochschr. Nr. 12, 1885.)

Virchow hat in einom Falle von Lepra, der auch den Kehlkopf schwer betroffen hatte, eine ilhm bisher unbekannte specifischo Elkrankung der Milz gefunden. Der Durchschnitt der vergrösserten Milz zeigte cine bunte Farbe, indem in der rothen Pulpa cine ungehenere Zahl kleinster, weicher, weisslich-grauer, rundlicher Körner oder Körperchen sichtbar wurden, kleiner und sehr viel zahlreicher als die gewöhnlichen Malpighi'schen Follikel. Die mikroskopischo Untersuchung erwies diese kleinen Körperchr’n angefüllt mit Leprabacillen und, wie aus dem Verhalten der Korne erkenntlich, unzweifelhaft hervorgrgangen aus progressiven $W$ ucherungsvorgängen. In dem Zusammentreffen von Bacillenhaufen und Wucherungsprocessen in cinem ziemlich abgelegenen Organe, das gerade beim Aussatz unverhältnissmässig wenig bethiligt schicn, sieht Virchow oine Bestätigung der Ansicht von der causalen Bedeutung der Bacillen.

Caspary.

Henning. Zwei Fälle von Pustula maligna, durch directe Uebertragung von einer milzbrandkranken Kuh entstanden. (Brit. med: Journ., 20. Sept. 1884.)

Am 30. April 1884 wurde eine des Milzbrandes verdächtige Kulh geschlachtet und ausgenommen. Fin Hund und eine Katze, die von den Eingeweiden derselben gefressen hatten, verendeten an Milzbrand. Von den beiden Männorn, welche die Tödtung, Ausweidung und Verbrennung des Cadavers besorgten, hatte der eine zu dieser Zeit eine Acne am Ellbogen, der andere eine frische Kratzwunde über dem einen Handrücken.

Am 11. Mai suchten beide Männer den Verfasser auf und boten dor erste am Ellbogen, der zweite am Handrücken je eine typische Pustula maligna dar. Im Contrum einen $1 \frac{1}{2}$ " messenden, runden, trockenen schwarzen Schorf, eingeschlossen von einer Reihe concentrisch angeordneter Bläschen und Pusteln, auf intensiv entzündetem Grunde. Oedem des Vorderarmes, respective Handrückens. Der erstere mit dem Knoten am Ellbog'n, ein Potator, bot aluch schwere all. 
gemeine ficberhafte Symptome dar und einen zwoiton Knoten am Vorderarme, der andere war von Allgemeinerscheinungen frei. Das Blut beider hielt Anthraxbacillen. Injectionen von concentrirter Carbolsüure in and um die Knoten brachte rasche Heilung in beiden Fällen.

Finger.

Küster. Demonstration zweier Fälle von multiplen Geschwülsten. (Berl. klin. Woch. Nr. 16, 1884.)

Küster berichtete in der Berliner medicinischen Gesellschaft über eine Anzalıl von Fällen theils solitärer elephantiastischer Goschwülste, theils multipler Neubildungen, und stellte zwei Kranko letiterer Art vor, deren einer Lipome, dor andere weiche Fibrome zeigte. Das grösste dieser Fibrome fand sich - hühnereigross oberhalb des rechten Ellbogengelenks, genan der Lage des Nervus radialis entsprechend; eine spindelförmige Geschwulst fester Consistenz darstellend, deren stärkere Berührung Schmerzen am Rücken der drei ersten Finger hervorrief. Dieses Neurom bestand seit fünfzehn Jahren in nahezu derselben Grösse, während die vielfachen Geschwülste der Hant und das Unterhantbindegowebe sich seit eilf Jahren eine nach der anderen zu solchen - bis Haselnussgrösso ontwickelt hatten.

Caspary.

Hyde. Ein Fall von multiplen Sarcomen der Haut. (London Medical Record, 16. Juni 1884.)

Ein 26 Jahre alter Belgier beobachteto zum trsten Male 1881 kleine Geschwülste auf seiner Körperdecke. Bis auf eine vor einigen Jahren mit Jucken und Schuppenbildung einhergehende Hantaffection ist keine Hautkrankheit erwähnt. Zunehmendes Wachsthum der Geschwülste, so dass zur Zeit der Aufnahme in Hyde's Klinik (Chicago) flachhandgrosse, das Hautniveau überragende Infiltrationsstellen $\mathbf{z u}$ sehen waren. Zwischen diesen grossen Geschwülsten waren kleinere, von der Grösse einer Erbse bis zu derjenigen einer Wallnuss zu constatiren.

Zwei Monate später war das Gesicht ganz entstellt, die Gliedmaassen mit einer Menge rother Geschwülste bedeckt und der Körper unbeweglich. Aufbruch einzelner Tumoren, Verfall der Kräfte und Fieber beschleunigten den letalen Ausgang. Die Section warde nicht gestattet, doch die vorgenommene mikroskopische Untersuchung der 
Geschwulstmassen ergab zweifellos ein Rundzellensarcom. Die Differential-Diagnose war gegenüber den läufigeren multiplen Fibromen der Haut und der Lepra zu machen.

Horovitz.

Behrend. Ein Fall idiopath ischer angeborencr Hautatroplie. (Berl. klin. Wochschr. Nr. 6. 1885.)

G. Behrend beschreibt in prägnanter Weiso einen Fall von idiopathischer angeborener Hantatrophie an einem höchst denden, 17 Monate alten Kinde, den wir mit den Wortrn des Autors wiedergeben: „Im Verhältnisse zu scinem Alter klein und mit ausserordentlich geringem Fettpolster verselıen, zeigte das Kind nur an seinen Clunes eine normale Beschaffenheit der Haut, die an den übrigen Körperstellen ein varschiedenes Ausselien hatte. Im Gesichte weiss, narbig glänzend, hart and geschrumpft lag sic dem Knochengerüste ziemlich dicht an, wodurch der Gesichtsausdruck verwischt und das Bild eines Mumienantlitzes erzeugt wurde. Durch die Schrumpfung waren die unteren Augenlider hochgradig ectropionirt unủ die Bindehalut derselben als rothe Wülste hervorgewölbt, so dass brim Lidschinss mehr als das nntere Drittel der Cornea unbedeckt blieb. Die Mfundwinkel abgerundet, die Mundöffnung narbig verellgt, die Haut dẹ Wangen narbig verkürct, schränkten die Ausgiebigkeit in den Bewegungen des Unterkiefers arheblich cin. Dabei lüsten sich an allen Stellen der Gesichtshaut von der an sich verdünnten Hornselichte dünne, weisse, seidenpapicrartige Schuppenlamellen ab, welche der Oberflitche beim Darüberstreichen eine gowisse Rauhigkeit vorliehen; sobald dic sonst regelmässig rorgenommene Application von Futtsalben auch nur wenige Tage unterbrochen wurde, traten oberflächliche Einrisse der Hornschichte auf, die sich zaweilen auch tiefer bis in das Corium erstreckten und cine zu dümnen Borken vertrocknende grlbliche oder mit Blut gemengte Flüssigkeit austreten liessen. Am Schädeldach und Hinterhaupt war die mit einem nur selır spärlichen Haarwachs bedeckte Haut papierdünn, glatt, auf der Unterlage verschieblich und frei von Schuppen. Am Runpf liess sich eine erhebliche Verdünnung oder narbige Schrumpfung der Haut nicht wahrnehmen; sie war beweglich und faltbar, zeigte jedoch ein sclımutzig. graues Aussehen und äberall eine Lockerung in den oberflächlichen Lagen der Hornschichte, die entsprechend den Hautfurchen in grössere oder kleinere unregelmitssige Felder getheilt war, in deren Peripherie 
die Abblätterung begann, um nach dem Centrum hin fortyschreiten. Intensiver verändert zeigte sich die Haut an den Extremitäten, wo sie den Weichtheilen fest anlag and namentlich den Unterschenkel wio cin Schnürstrumpf umgab. Während jedoch die Hände bei narbiger Retraction des Corinm ganz wie das Gesicht eine fein-lamellöse Abschilferung der Hornschiclite darboten, hatte diesclbe an den Buinrn und Füssen mit Einschluss der Fusssohlen eine harte pergamentartige Beschaffenheit, gelbbraune Färbung und löste sich in grossen Fetzen ab. Nach solcher Ablösung trat eine anscheinend normal gefärbte und mit einer weichen, zarten Epidrrmis belrleidete Stelle zu Tage, die sehr bald, mitunter schon nach 24 Stunden hart wurde, sich dunkler fürbte, glänzend wurde, sich verdickte und wieder ablöste - und so wiederholte sich der Process in typischer Weise in ununterbrochener Reihenfolge. Ein besonderes Interesse boten dic Finger und Zehen dar. Während die letzteren mehr kurzen warzigen Stummeln als gegliederten Zehen glichen, waren jene dünn und lang, nach der Spitze za verjüngt, in Extensionsstellang fixirt, so dass sio nur und wenig in den Metacarpophalangealgelenken sich beugen liessen. Die sie bedeckendo Haut war dünn, glänzend und straff, genau wie bei der Sclerodactylie. Der Ringfinger der linken Hand, welcher dasselbe Aussehen gehabt haben soll, war schon im sechsten Lebrnsmonat zu einem dünnen fadenartigen Strange vertrocknct und nhne Eiterung abgefallen. Die Nägel an Fingern und Zehen waren gryphotisch gleich Hühnerkrallen bis auf die in fünften Lebens. monate normal gewordenen Nägrl der Daumen- and Zeigefinger. Die Affection hatte sich in utero entwickelt, während des Extrauterinlebens aber stetig gesteigert. Unmittelbar nach der Geburt des Siebenmonatiindes fielen den Eltern die narbige Schrumpfung und das Ectropium beider unteren Angenlider, die steifen Finger, die Hühnerkrallen-Nägel auf. Nach wenigen Tagen begann die Abschilferung im Grsichte, während die übrige Haut eine bräunlich-gelbe Fürbung annalim und pergamentartig lart wurde, fest wie eine 'Irommel nach dem Ausdrucke der Fltern, and dir Abschilferung begann, anfangs in kleinen Schuppen, später in grossen Lamellen." Belnend fasst den Krankheitsfall als idiopathische Hautatrophie auf, bei dem in Gesichte und an den Händen mehr die Atrophie des Corium, an den übrigen Stelien die Atrophie der Epidermis (Keratolyse in Sinne A uspitz's) in den Vordergrund getreten sei. In der Literatur hat er nur einen fast 
gleichen Fall (Seligmann, de epidermidis, imprimis neonatorum desquamatione. Diss. inauguralis. Berol. 1841) gefunden, bei dum aber die Hant der Finger und wohl auch des Rumpfes viele Falten bildete, ähnlich dem Xeroderma non pigmentosum Kaposi.

Cas pary.

\section{Dermatomykosen.}

(Pilzkrankheiten der Haut nnd ihrer Auhänge.)

Weyl. Ueber Erythras ma. (Monatsh. für prakt. Dermatol, Bd. III. Nr. 2 und 3. 1884.)

Weyl fand in den als Mehl von den kupferfarbenen Flecken abstreichbaren Schüppchen bei "Erythrasma" folgende charakteristische Elemente: Kurze, schmale, sehr blasse, wenig gebogene, dann starre und sehr lange, zuweilen aus 2-3 Gliedern zusammengesetzte Fädchen. Selten bestanden einzelne Fädchen aus perlschnurartig aneinander gereihten, abgeplatteten Gliedern. Endlich sah W. auch wellenförmig gewundene, sehr blasse, schmale, mehr oder minder lange Fäden. Der Breitendurchmesser beträgt zumeist weniger als $0.6 \mathrm{Mm}$., die Länge ist verschieden. Wo das Netz am dichtesten, dort sind die Fäden an kürzesten. Verzweigung and Gonidionbildung war nirgends wahrzunehmen. Die Fortpflanzung scheint jene der Spaltpilze zu sein. Die Pityriasis sei in der Leistengegend etwas Gewölnliches, nicht so das wirkliche Erythrasma. In dem Masse nun, als von dem kupferrothen Erythrasma sich Uebergänge zu der kaffeebraumen Pityriasis versicolor fänden, trete auch entsprechend häufig das Mikrosporon furfur auf, welches sich aber von den Elementen des Erythrasma deatlich unterscheiden lasse.

Horovitz.

Köbner. Erythrasma. (Monatsh. für prakt. Dermatulogie, Bd. III. Nr. 12. 1884.)

Köbner weist darauf hin, dass er im Jahre 1866 die einzige, bisher bekannte experimentelle Uebertragung des Erythrasma in der medicinischen Section der schlesischen Gesellschaft für vaterländische Cultur zu Breslau demonstrirt hatte. Erst dieses Experiment habe die vermuthete ätjologische Bedeutung des Burckhardt'schen Mikrosporon minutissimum erwiesen. Das Erythrasma sei, dies werdo ans dem beigadruckton Sitzungsprotokolle klar, weder mit dem Eczema 
marginatum, noch mit Herpes tonsurans zu identificiren. K. hält die mikroskopische Unterscheidung des Mikrosporon minutissimum von Trichophyton tonsurans für leicht, was besonders in Fällen, wo das Erythrasma neben Pityriasis versicolor am Rumpfe sich findet und in allen klinisch zweifelhaften Fällen von muthmasslichen parasitüren Hautaffectionen der Inguinocrural- und Achselgegend von Wichtigkeit ist.

Horovitz.

Riehl. Ueber Erythrasma. (Wiener medic. Wochenschrift Nr. 14 and 42,1884 .)

Die Krankheit sei eine häufge, gehüre dem besten Mannesalter an; bei Frauen und Kindern sowie im hüheren Alter komme sie selten vor. Der jüngste Kranke war 16, der älteste 55 Jahre alt. Achselhöhle und Innenfläche der Oberschenkel sind die Lieblingssitze; manchmal aber kriechen die Flecke serpiginös weiter, so dass R. in einem Falle die obere Grenze über der Symphyse fand. - In einem Falle fand sich das Erythrasma nebst ausgebreiteten Flecken im Schenkeldreieck auch in Thalergrösise zerstreut an den Extremitäten sowie in Stecknadelkopfgrösse zerstreut über dem ganzen Stamme. Der Verlauf ist ein eminent chronischer, selten kommt es zu acuten Nachschüben; im. Alter scheine es von selbst zu schwinden. Bei der mikroskopischen Untersuchung werde jeder diagnostische Zweifel durch die Zartheit der PiJzelemente (Milirosporon minutissimnm), die durch das ganze Sehfeld zerstreuten kleinen Gonidien benommen. Das Mycelium zeigte a) einfach röhrenförmige Gebilde, b) ähnliche septirte Elemente, c) dichotomisch verzweigto Fäden, d) knopfförnig am Ende aufgetriebene Elemente, e) radiäro, quirlförmige Anordnung der Elemente.

Der Sitz der Pilze ist die Hornschichte der Oberhaut, durch aufeinanderfolgende Anwendung von alkal. Metlyylenblaulüsung and schwachessigsaurer Bismark-Braunlösung gelinge es, die Pilzelemente braun, die Epidermis blassblan zu färben. Ueber Züchtung und experimentelle Uebertragung des Mikrosporon minutissimum liegen nach Riehl bisher keine Mittheilungen vor, auch hätten seine eigenen diesbezüglichคn Versuche keine unanfechtbaren Resultate gehabt. (Siehe das Referat über Erythrasma von Köbner.)

Horovitz.

Behrend. Ueber I mpetigo contagiosa. (Deatsche med. Wochenschrift Nr. 48, 1884.) 
Behrend stellte am 17. November $1884 \mathrm{im}$ Vercine für innere Medicin in Berlin einen Knaben vor, der vor 8 Tagen in seine Behandlung kam. Derselbe zeigt im Gesichte eine Hautkrankheit, welche man als Impetigo contagiosa bezeichnen musste, zugleich waren am Nacken, auf beiden Schultern and am beharten Kopfe typisclie Flecke von Herpes tonsurans, in deren Schuppen sich Mycelien und Sporen nachweisen liessen. Vor 6 Wochen hatte B. in der Poliklinik zwei ähn. liche Fälle beobachtet. In allen diesen Fällen waren dio Submaxillardrūsen erheblich angeschwollen and schmerzhaft. $O b$ nun Impetigo contagiosa eine besondere Form des Herpes tonsurans sei, oder ob der Pilz der Impetigo contagiosa Herpes tonsurans ähnliche Effloresceuzen bewirken könne, darüber will B. keine bestimmte Meinung abgreben.

Horovitu.

Colcott Fox. Impetigo vel Porrigo contagiosa. (Med. Soc. Transact. 1884.)

Der Autor kommt nach Durchsicht der Literatur und auf Grund eigener Beobachtungen zu dem Schlusse, dass die als Impetigo contagiosa bezeichnete Affection in vielen Fallen durch eine abnorme Wucherung von Trichophyton tonsurans bedingt sei, dass aber in einer grossen Reilıe von Fällen dieses ätiologische Moment nicht horangezogen werden könne, sondern dass es sich hiebei sehr oft lediglich um Infection erodirter Hautpartien init eitrigem Secret der verschiedenartigsten Natur hạ deln könne. So wird das Auftreten von Impetigo. formen nach der Vaccination (Tilbury Fox) durch Infection der Haut mit Vaccinepusteleiter erklärt. (Ist gewiss nur schwer nachzuweisen. Pef.)

Hochsinger.

Kaposi. Ueber einen Fall von Favus universalis. (Sitzungsb. der Wiener Ges. d. Aerzte vom 17. Oct. 1884.)

Kaposi stellte am 17. October 1884 einen 40jührigen Mann der Gesellschaft der Aerzte vor, an welchem nicht der behaarte Kopf allein mit den charakteristischen Favusscutulis bedeckt, sondern Favus noch an anderen Stellen des Körpers reichlich anzutreffen war. Wenn Favus an mit Lanugo bedeckten Stellen auftritt, so geschieht dies auf dreierlei Weise: Erstens durch Selbstübertragung wie im gegenwärtigen Falle, vom Kopfe auf die übrigen Körpertheile; «weitens unter dem Einfusse macerirender Umschlägo und drittens anf künstliche 
Weise durch das Experiment. In dem vorgestellten Falle ging die Entwicklung des Favus universalis ungemein rasch vor sich. Während am 25. September über dem linken oberen Augenlide und gegen die Jochbeingegend kaum einige stecknadelkopfgrosse Scutula anzutreffen waren, sind heute, also nach circa 5 Wochen, die Streckseiten der oberen und unteren Extremitäten, die Haut des Stammes, des Gesichtes mit mäçhtigen dichtgehäuften Scutulis besät. An der Beugefläche der Unterschenkel sind die Favi in Folge der intensiv-reactiven Entzündung ausgefallen und an deren Stelle flachnarbige Depressionen zurückgeblieben. Favus der Fingernägel. Die einzelnen Farus. efflorescenzen sind roth gesäumt und ihre Umgebung entzündet.

Horovitz.

Schütz. Ueber das Eindringen von Pilasporen in die A thmungswege und diedadurch bedingten Erkrankungender Lungen und über den Pilz des Hühnergrindes. (Mittheilungen aus dem k. Gesundheitsamt. Bd. II. p. 208-227. 1884.)

Den Schluss einer Abhandlung von Schütz über Pilzsporen in den Athmungsorganen bildet eine kurze Mittheilung über den Hühnergrind (Tinea, Favus, Porrigo galli), welch letzterer in einer Pilzerkrankung des. Kammes und Kehllappens der Hühner bestellt, wobni die genannten Gebilde schliesslich in toto von confluirenden grauweissen Schuppen überzogen werden. Der Process schreitet später auch auf Hals, Brust und Rumpf fort. Es gelang dem Autor den Pilz auf Fleischpeptongolatine, so wie auf anderen Nïhrmedien (u. A. auch Kartoffeln), ganz besonders gut auf Brotdecoct zu züchten und mit den Reinkulturen bei vorher intacten Thieren die gleiche typische Erkrankung des Kammes za erzengen. Der Pilz besteht aus gegliederten und verzweigten Fäden, deren ältere Elemente breiter und kürzer sind, als die blassen und fast durchsichtigen jüngeren. Meerschweinchen, weisse Mäuse, Ratten etc. verhielten sich gegen die Impfungen refractîl.

Izquierdo. Spaltpilze bei der Verruga peruana. (Virchow's Archiv. Band 99, Heft 3. 1884.)

Izquierdo hat bei einem Falle von Verruga pernana Untersuchungen üher das Vorhandensein von Mikroorganismen angestellt. Die untersuchten Knoten stammten von einem Kranken, der seinem Leiden erlegen war und waren 10 Stunden post mortem aus der Kniegegend 
und Vorhaut entnommen and in Alkohol gehärtet worden. Insbesondere bei der Behandlung mit Gentianaviolett zeigten sich vielfach in den Knoten kettenfürmig argeordnete Mikrococcen. Izquierdo spricht auch von grōsseren und kleineren Bacterien, versteht aber darunter die verschieden langen Ketten. Die Capillaren der sehr blutgefässreichen, sarkomähnlich gebauten, Neoplasmen des Bindegewebes vorstellenden Knoten waren zum Theil durch Coccenmassen vollständig verstopft and hatten an solchen Stellen häufig variköse Auftreibungen. Es fanden sich die Mikrococcen auch in Capillaren und Venen, selten in den kleinen Arterien makroskopisch gesund erscheinender Haut in einiger Entfernung nm die Knoten hernm, ebenso wie in den Gefässen der die Knoten bedeckenden Haut.

Caspary.

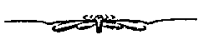

